\title{
High-frequency identification of monetary policy shocks in Japan
}

\author{
Hiroyuki Kubota $^{1} \cdot$ Mototsugu Shintani $^{1}$ (D)
}

Received: 28 December 2020 / Revised: 24 November 2021 / Accepted: 25 November 2021 /

Published online: 24 January 2022

(C) Japanese Economic Association 2022

\begin{abstract}
We identify monetary policy shocks in Japan during the unconventional monetary policy period using high-frequency data for interest rate futures. Following the empirical strategy of Gürkaynak et al. (Int J Cent Bank 1: 55-93, 2005), we conduct an event-study analysis to estimate the effects of the monetary policy surprises on asset prices around the timing of policy announcements made by the Bank of Japan between 1999 and 2020. We find that a monetary policy shock can be described by two factors that have statistically significant effects on the financial market. A surprise monetary tightening has negative effects on stock returns and positive effects on government bond yields, even in the low-interest environment. We also find that the responses of the longer term yields tend to be larger than those of the shorter term yields. The response is the largest for the 10-year government bond yield, which has, in the last 2 decades, been effectively targeted by the Bank of Japan. This finding contrasts with those of previous studies of the conventional monetary policy period, in which responses are larger for the shorter term yields.
\end{abstract}

Keywords Unconventional monetary policy $\cdot$ High-frequency event study $\cdot$ Zero lower bound

\footnotetext{
An earlier version of this paper was circulated under the title "High-Frequency Identification of Unconventional Monetary Policy Shocks in Japan." The authors would like to thank the editor, two anonymous reviewers, Kosuke Aoki, Naoko Hara, Ryo Kato, Ichiro Muto, Taisuke Nakata, Makoto Nirei, Masahiko Shibamoto, Shigenori Shiratsuka, Yu Sugisaki, Kazuhiro Teramoto, Yinxi Xie, and the seminar participants at the Bank of Japan, Osaka University, and the University of Tokyo for their helpful comments and discussions. Shintani gratefully acknowledges the financial support of the Grant-in-Aid for Scientific Research (20H01482).
}

Mototsugu Shintani

shintani@e.u-tokyo.ac.jp

Hiroyuki Kubota

kubota-hiroyuki916@g.ecc.u-tokyo.ac.jp

1 The University of Tokyo, Tokyo, Japan 
JEL Classification E43 $\cdot$ E44 $\cdot$ E52 $\cdot$ E58 $\cdot$ G14

\section{Introduction}

As a result of a decreasing trend in the natural rate of interest, controlling the shortterm interest rate as a policy instrument is more likely to be constrained by the zero lower bound (ZLB) in many advanced countries. When there is no room to lower the policy rate in response to large negative shocks in the economy, such as the global financial crisis in 2008 or the outbreak of COVID-19 in 2020, central banks have no choice but to rely on unconventional policy instruments, including government bond purchases and forward guidance. Among central banks in such an environment, the Bank of Japan (BOJ) is notable in having conducted a series of unconventional monetary policies for nearly 2 decades, since the time the zero-interest rate policy was first introduced in 1999. One of the main channels of unconventional monetary policy is to change the expectations on the future path of interest rates without using the short-term rate as the policy instrument.

In this paper, we investigate the effect of monetary policy on the financial market during the unconventional monetary policy period in Japan using information from the high-frequency data on interest rate futures, which reflects the future expectations of the market participants. Our identification strategy closely follows that of Gürkaynak et al. (2005), who measured monetary policy surprises in the US, using changes in federal fund futures and 3-month Eurodollar futures in a sufficiently narrow window of time around the Federal Open Market Committee (FOMC) press releases. Likewise, we measure monetary policy surprises in Japan, using changes in 3-month Euroyen futures and 10-year Japanese government bond (JGB) futures, around the Monetary Policy Meeting (MPM) press releases between 1999 and $2020 .{ }^{1}$ Using the changes in asset prices in a corresponding time interval, the market responses to monetary policy shocks can be appropriately evaluated, because the effects of other macroeconomic news are likely to be excluded. ${ }^{2}$ Gürkaynak et al. (2005) also claim that monetary policy surprises can be characterized by two factors with a structural interpretation: the "target" factor, which mainly affects the current short-term rates, and the "path" factor, which affects the expected path of future short rates. In a similar vein, we consider the possibility that monetary policy surprises can be summarized by a small number of common factors in Japan. For robustness, we also extend the analysis of Gürkaynak et al. (2005) by extracting factors from the surprises around other monetary policy events, such as the press conferences.

\footnotetext{
${ }^{1}$ The monetary policy surprise series used in this paper is available from the authors upon request.

2 According to Altavilla et al. (2019), changes in the policy stance that are orthogonal to the information set of market participants are called (market-based) policy surprises, while changes that are orthogonal to the state of the economy are called policy shocks. However, we use two terms interchangeably throughout the paper.
} 
Our findings from the estimated responses of the stock prices and the government bond yields to the monetary policy surprises can be summarized as follows. First, two factors are found to be useful in describing market surprises in Japan, even in the low-interest environment. In response to both the target and path factors of the surprise monetary tightening, the government bond yields increase and the stock prices decline. The directions of these responses are consistent with the standard theoretical predictions and the coefficients are statistically significant. These results for Japan are similar to those for the US, as obtained by Gürkaynak et al. (2005) and Swanson (2021). Second, the responses to both factors tend to be larger for the longer term government bond yields and smaller for the shorter term government bond yields. In particular, among the longer term government bond yields, the size of the responses is largest for the 10-year JGB yield, which has effectively been considered as the policy target in the last 2 decades by the BOJ. This finding is in contrast with the previous studies using the data from the conventional monetary policy period by Gürkaynak et al. (2005) for the US and by Honda and Kuroki (2006) for Japan, who find that the response of government bond yields to a monetary policy shock is smaller for the longer maturities. At the same time, our results are in line with responses to factors that represent the unconventional monetary policy channels, estimated by Swanson (2021) for the US. We conjecture that this difference between the conventional and unconventional monetary policy periods comes from the ZLB, which imposes a stronger restriction on the variation in yields with shorter maturities. Our results imply that the BOJ has been successful in controlling the long-run expectations on the interest rates through monetary policy announcements.

Honda and Kuroki (2006) is one of the first analyses to employ the identification methodology of Kuttner (2001) and measure monetary policy surprises for the conventional monetary policy period in Japan, based on the daily data of Euroyen futures rates. For the unconventional monetary policy period in Japan, Arai (2017) identifies the monetary policy shocks using the daily changes in the JGB spot yields. Furthermore, Nakashima et al. (2020) use the the multiple common factors extracted from daily surprises in Euroyen futures rates and other financial series to identify the various types of the unconventional monetary policy shocks. There are also several studies that employ high-frequency data of futures interest rates to identify the monetary policy shocks in Japan. For example, using the monetary policy surprises obtained from the intraday data of JGB futures, Rogers et al. (2014) evaluate the effects of the unconventional monetary policy, while Cieslak and Schrimpf (2019) investigate the central bank communication channel. Nakamura et al. (2021) follow Nakamura and Steinsson (2018) in identifying monetary policy shocks using a single factor from the intraday data of Euroyen futures and discuss the importance of a tight window.

The remainder of the paper proceeds as follows. In Sect. 2, the policy surprises around the press releases are measured using high-frequency data for interest rate futures. The event study regression results, which are based on the policy surprises in each futures rate, are reported in Sect. 3. The regression results based on the multiple common factors among the Euroyen futures surprises are reported in Sect. 4. In Sect. 5, the robustness analyses of the baseline results by incorporating monetary 
policy events other than the press releases, and by adding the JGB futures surprises in extracting factors, are conducted. Concluding remarks are presented in Sect. 6.

\section{Futures market and monetary policy meetings}

\subsection{Monetary policy surprises}

In this section, we describe our intraday series and the methodology used to construct our monetary policy surprises. We employ the Euroyen futures and the JGB futures to measure the policy surprises. ${ }^{3}$ The Euroyen futures are contracts for the 3-month Tokyo Interbank Offered Rates (TIBOR) on a specific future date. ${ }^{4}$ Since the Euroyen futures are traded for multiple contract months, we collect four series; 3-, 6-, 9-, and 12-month ahead Euroyen futures rates, which will be denoted by EYF3, EYF6, EYF9, and EYF12, respectively. Note that EYF3 reflects the current expectation of the 3-month interest rate after 3 months at longest. Similarly, EYF6 (EYF9 and EYF12) reflects that of the same rate after 6 (9 and 12) months at longest. Accordingly, the surprises in four Euroyen futures contain information on unexpected changes in the 3-month rate up to 1 year ahead. In what follows, we refer to surprises obtained from four Euroyen futures data as EYF surprises.

The JGB futures are futures contracts for a hypothetical 10-year JGB. Since we use only JGB futures with a nearby month, policy surprises reflect unexpected changes in up to 3-month ahead long-term rates. It should be noted that the expected long-term rate, which is reflected in the JGB futures, is also informative regarding the expected path of short-term rates. ${ }^{5}$ In what follows, we refer to JGB futures as JGBF.

Monetary policy surprises are measured by the difference between the futures rate $10 \mathrm{~min}$ before and the futures rate $20 \mathrm{~min}$ after the monetary policy announcement. Here, the monetary policy announcement refers to various types of events that are related to officially releasing information on the monetary policy by the central bank. ${ }^{6}$ As a baseline choice in determining the elements comprising a monetary

\footnotetext{
3 See Appendix A for the data sources.

4 TIBOR is the prevailing interest rate in the Japan Offshore Market (JOM). As the futures contract equivalent to the Federal Fund futures in the US, overnight call rate futures can also be used in Japan. It is a futures contract for the uncollateralized overnight call rate, which was the main policy target of the BOJ during the conventional monetary policy period. However, the data for overnight call rate futures are available only in the period from 2007 to 2017. In contrast, high-frequency data for Euroyen futures, as well as JGB futures, are available for the past 20 years, which corresponds to the entire period of unconventional monetary policy.

5 Since the JGB futures are written on a hypothetical 10-year JGB with coupons, to calculate changes in the expected long-term yield from the JGB futures prices, we approximate the change in the yield of the cheapest-to-deliver with the rate of change in the futures prices. As in the case of Cieslak and Schrimpf (2019), we calculate the rate of change in prices divided by the negative of the maturity of the cheapest. For simplicity, we uniformly consider the maturity of the cheapest as seven, as Hattori (2019) points out that the 7-year JGB has been the cheapest in Japan.

6 According to the terminology used by Gürkaynak et al. (2005), the announcement refers to "any means
} 
policy announcement, we focus on the press release called the "Statement on Monetary Policy," which is made available immediately after each MPM. While our choice of the type of announcement closely follows that of Gürkaynak et al. (2005), other choices characterizing the monetary policy announcement are later considered in Sect. 5. MPMs have been regularly held once or twice a month since the revision of the Bank of Japan Act in January 1998. The frequency of the MPMs is later set at eight times a year from January 2016. After the BOJ decided to hold the MPMs on a regular basis, the schedule of MPMs was made public in advance. In general, the market participants can revise their expectations on the future interest rate in response to any news on the prospects of the economy, rather than to the news specifically on the monetary policy conducted by the central bank. By taking a tight 30-min window around the policy announcements, we expect to capture the revisions of the market's expectations purely caused by monetary policy without being affected by other shocks. ${ }^{7}$

Since the intraday data of Euroyen futures are available from September 1999 through February 2020, we construct five series of monetary policy surprises around 280 press releases from the corresponding period. ${ }^{8}$ Because the zero-interest policy was first introduced in Japan in 1999, our sample covers most of the unconventional monetary policy period when the ZLB was binding. It should be noted that we follow Nakashima et al. (2020) and exclude four MPMs from the sample, when other news than the BOJ policy announcement were likely to be revealed tight around the timing of the policy announcement. Specifically, September 18, 2008, September 29, 2008, and November 30, 2011 are excluded for international coordinated policy actions at the same time, and March 14, 2011 is excluded for the East Japan Earthquake. ${ }^{9}$

\subsection{Intraday changes in futures rates in the selected days with policy announcements}

To illustrate how the monetary policy announcements affect market expectations, we plot changes in EYF3 in Fig. 1 on three selected dates of the MPMs. Note that

\footnotetext{
Footnote 6 (continued)

by which a policy decision was communicated to financial markets, including open market operations as well as explicit press releases (p. 57)."

7 Gürkaynak et al. (2005) show that measuring surprises within a tight window successfully eliminates the effects of the employment statistics releases in the morning of the FOMC dates. While this issue does not always apply to Japan, there are some cases when government statistics were released in the morning on the days of the MPM. For example, on January 23, 2019, the Ministry of Health, Labour and Welfare released the latest result of the Monthly Labor Statistics Survey at 9:00 a.m., and the MPM press release was announced at 11:59 a.m. on the same day.

8 We describe the procedure of measuring the monetary policy surprise in detail in Appendix B.

9 On September 18, 2008, September 29, 2008, and November 30, 2011, multiple central banks announced coordinated actions at the same time, and therefore, the identification of monetary policy surprises from MPM press release is difficult. On March 14, 2011, the market was highly volatile on that day, due to a number of news bulletins regarding damages caused by the East Japan Earthquake, which leads to confounders.
} 
a decline in EYF3 implies a decline in the expected future short-term rate. Panel (i) shows the changes in EYF3 on January 29, 2016 when the BOJ introduced a negative interest rate policy. We can observe a sharp drop in EYF3 tight around the press release at 12:38 p.m. This change suggests that the announcement was to some extent unanticipated, and the market participants revised their expectation on the short rates downward in response to the announcement. ${ }^{10}$

Panel (ii) shows the changes in EYF3 on April 4, 2013 when the BOJ introduced the Quantitative and Qualitative Monetary Easing (QQE) policy. The QQE includes (1) the policy target change from the uncollateralized overnight call rate to the monetary base; (2) the long-term bond and ETF purchases; and (3) the forward guidance. Although it was one of the largest policy actions in the last 2 decades, the EYF3 surprise was 0.5 basis points. This result implies that the policy action had almost been anticipated prior to the press release at 1:40 p.m.

Panel (iii) shows the changes in EYF3 on July 29, 2016 when the BOJ enhanced the monetary easing by increasing the pace of purchasing ETF twice as fast as before. A rise in EYF3 shortly after the press release implies that the monetary decision led to an upward revision of the expected short-term rates. In this case, we can deduce that the actual monetary decision was perceived as a disappointment by the market participants, and that the futures rates responded in the opposite direction to the policy decision. This conjecture can be confirmed by the CNBC article explaining that the market had expected further monetary easing actions on that day. ${ }^{11}$

\subsection{Comparisons with the conventional monetary policy period}

Let us compare the surprise series in the unconventional monetary policy period with those in the conventional monetary policy period before 1999. For the unconventional monetary policy period, we consider the "wide" window surprises measured within a 1-h window and the "daily" window surprises, along with the "tight" window surprises within a 30-min window. ${ }^{12}$ For the conventional monetary policy period, we consider two measures of EYF3 surprises. The first surprise measure is the daily window EYF3 surprise. We measure the surprises around MPMs for the period from 1998. As MPMs had not been held until 1998, we measure the daily surprise based on the policy change dates specified by Honda and Kuroki (2006). While Honda and Kuroki (2006) claim that the information on the policy changes

\footnotetext{
10 Further observation of panel (i) suggests that the futures rate began to move a few minutes before the press release. This fact implies some possibility of information leakage about the decisions made in the MPM. However, the 30-min window can capture such early movements up to 10 min before the announcements. While there are trade-offs in capturing the information leakage beyond 10 min using a wider window and the identification of pure monetary surprises, we later show that a 30-min window is a reasonable choice in the event study regressions.

11 The July 29, 2016 CNBC article, "Nikkei whipsaws after BOJ disappointment; yen surges against dollar" reported that "the Bank of Japan threw markets a smaller-than-expected bone in a keenly watched decision on Friday." It also reported that "it didn't change interest rates or increase the monetary base, as analysts had widely expected," while the BOJ decided to increase ETF purchases.

12 The wide window surprise is the difference between the futures rate $15 \mathrm{~min}$ before and the futures rate $45 \mathrm{~min}$ after the announcement, and the daily window surprise is the difference between the closing rate before and the closing rate after the announcement.
} 
(i) January 29, 2016 (March 2016 Contract)

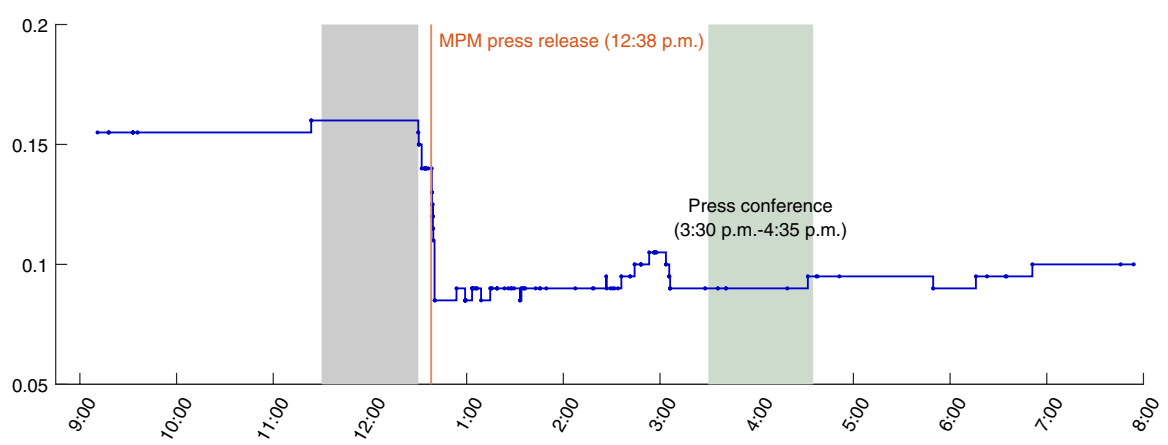

(ii) April 4, 2013 (June 2013 Contract)

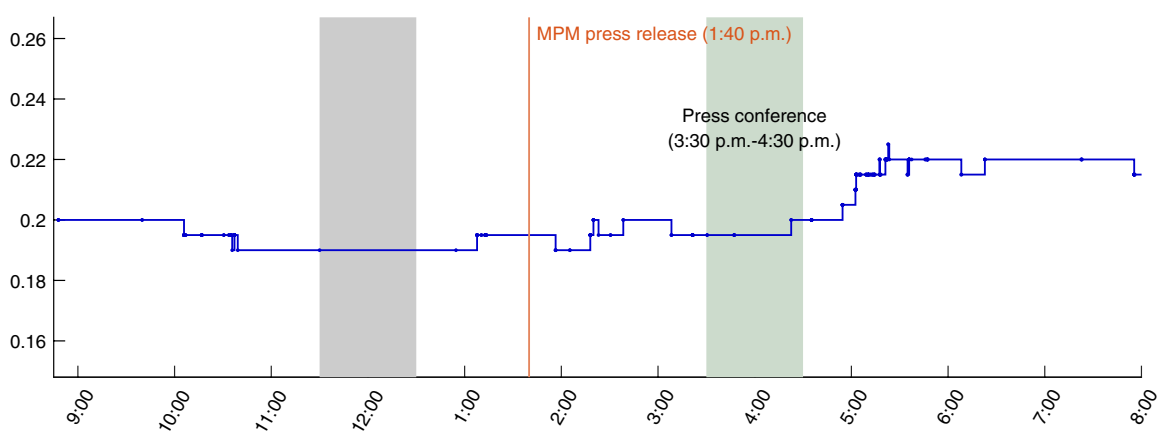

(iii) July 29, 2016 (September 2016 Contract)

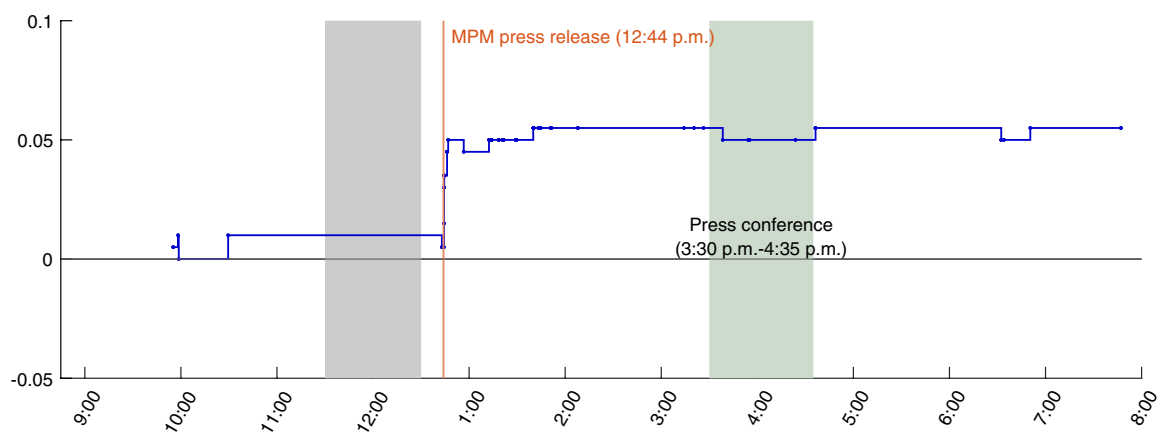

Fig. 1 Intraday changes in the Euroyen futures rate (1). Note: Panels i-iii show the 3-month ahead Euroyen futures rates (percentage) on the three selected MPM dates: January 29, 2016, April 4, 2013, and July 29, 2016. The times of the press releases are indicated by the vertical lines for every panel. The darker shaded area indicates the lunch break for the Euroyen futures market (11:30 a.m.-12:30 p.m.), and the lighter shaded area indicates the press conference for the explanation of the policy decisions in the MPM 
had been transmitted gradually in Japan and employ windows wider than the daily window, we measure the daily surprise around the beginning date of every policy change. The second surprise measure is the original series constructed by Honda and Kuroki (2006), using windows wider than a day.

The left panel of Fig. 2 shows the empirical distributions of the three surprise series from the unconventional monetary policy period, while the right panel shows those of the two surprise series from the conventional monetary policy period. We observe that the daily window surprises for the conventional monetary policy period are negatively biased, as the null hypothesis of the zero mean is rejected at the 5\% significance level. In contrast, the unbiasedness hypothesis is not rejected for the surprise series of Honda and Kuroki (2006). It is also clear that the standard deviation of daily window surprises has become much smaller in the unconventional monetary policy period. From the $F$-test statistic of 26.615 , we reject the null hypotheses that the standard deviations of daily window surprises are the same between the conventional and unconventional monetary policy periods, in favor of a larger standard deviation in the conventional monetary policy period at the $1 \%$ significance level. The same is true when we compare the standard deviation of daily window surprises in the unconventional monetary policy period and that of Honda and Kuroki (2006)'s surprise series with the $F$-statistic of 142.416. This result suggests that the expectations on the short rates fluctuate within a wider range during the time when the short-term rate is not constrained by the ZLB. ${ }^{13}$

\subsection{Advantages of the tight surprise over the daily surprise}

Using the time series plot is also useful in understanding the effect of choosing the window size on the measure of the monetary policy surprises. Figure 3 plots the tight window and the daily window EYF3 surprise series in the top and bottom panel, respectively. In this figure, we observe three events when the difference between the two surprise series is larger than 5 basis points. These three dates, shown as (a), (b), and (c) in the figure, provide useful case studies for understanding the source of the difference between the tight window surprises and daily window surprises. Figure 4 shows the intraday changes in EYF3 for the corresponding three events.

For December 19, 2006 in panel (a) and January 22, 2008 in panel (b), the tight window surprises are smaller than the daily window surprises. First, for December 19,2006 , both the tight window surprise and the daily window surprise are negative, but the latter is much larger in size. In fact, the change at the time of the end of the press conference accounts for a large fraction of the daily window surprise. Second, for January 22, 2008, the Euroyen futures rate hardly changed within the 30-min

\footnotetext{
13 In Appendix C, we make further comparisons among these monetary policy surprises for the conventional and unconventional monetary policy periods.
} 
window around the MPM press release. ${ }^{14}$ However, the daily window surprise is large and negative, because the Euroyen futures rate varied throughout the day, due to drastic falls in stock prices, the speech in the governor's press conference after the MPM, and speculation on an emergency rate cut in the US. ${ }^{15}$ These two examples imply that the effects from events other than the press release are likely to be excluded from the 30-min window surprises.

For December 1, 2009, in panel (c), both the tight and daily surprises are large in size but in the opposite directions. On that day, the BOJ held an unscheduled MPM and announced the resumption of the quantitative easing (QE) for the first time in 4 years. Despite the BOJ's decision, the tight surprise indicates the largely positive, i.e., contractionary surprise. It is considered to be a similar case to what we have observed for July 29, 2016 in panel (i) of Fig. 1. Specifically, the market had anticipated a further monetary easing in response to the announcement to hold the unscheduled MPM, which was released in the morning on this day. It is reasonable to conclude that the market expected that the situation would be considered urgent and some policy actions would be decided. We can make this conclusion from a striking decline around the announcement to hold the unscheduled MPM, which is larger than a rise around the press release. Accordingly, the fact that the tight surprise on that day was positive should imply that the policy action actually decided was not as strong as the market had expected $10 \mathrm{~min}$ before the press release of the statement. The market participants felt disappointed with the actual decision, once it was revealed.

In what follows, we mainly use the 30-min window around the MPM press releases as a baseline in our analysis. On the other hand, the three examples above suggest that other monetary policy events, such as the press conferences and the announcements to hold the unscheduled meetings, may change market expectations. For this reason, later in Sect. 5, we also incorporate other types of policy events in the analysis.

\footnotetext{
${ }^{14}$ If we simply measured the 30 -min surprise on this day, it would be zero, since the 30-min window around the MPM press release is within the lunch break in the Euroyen futures market. To avoid this situation, we set the 30-min windows, excluding the trade breaks. We describe this point in Appendix B.

${ }^{15}$ According to the news articles, speculation that the Fed would hold an unscheduled meeting (FOMC) and decide a rate cut had been spreading throughout the day. The Fed actually held a meeting and announced a drastic rate cut around 10 p.m., which was after the Euroyen futures market had closed. We also note that the difference between the closing price on the day and the opening price on the next business day for the Euroyen futures was very small. This observation implies that the decisions of FOMC had been almost anticipated by the time the market closed.
} 

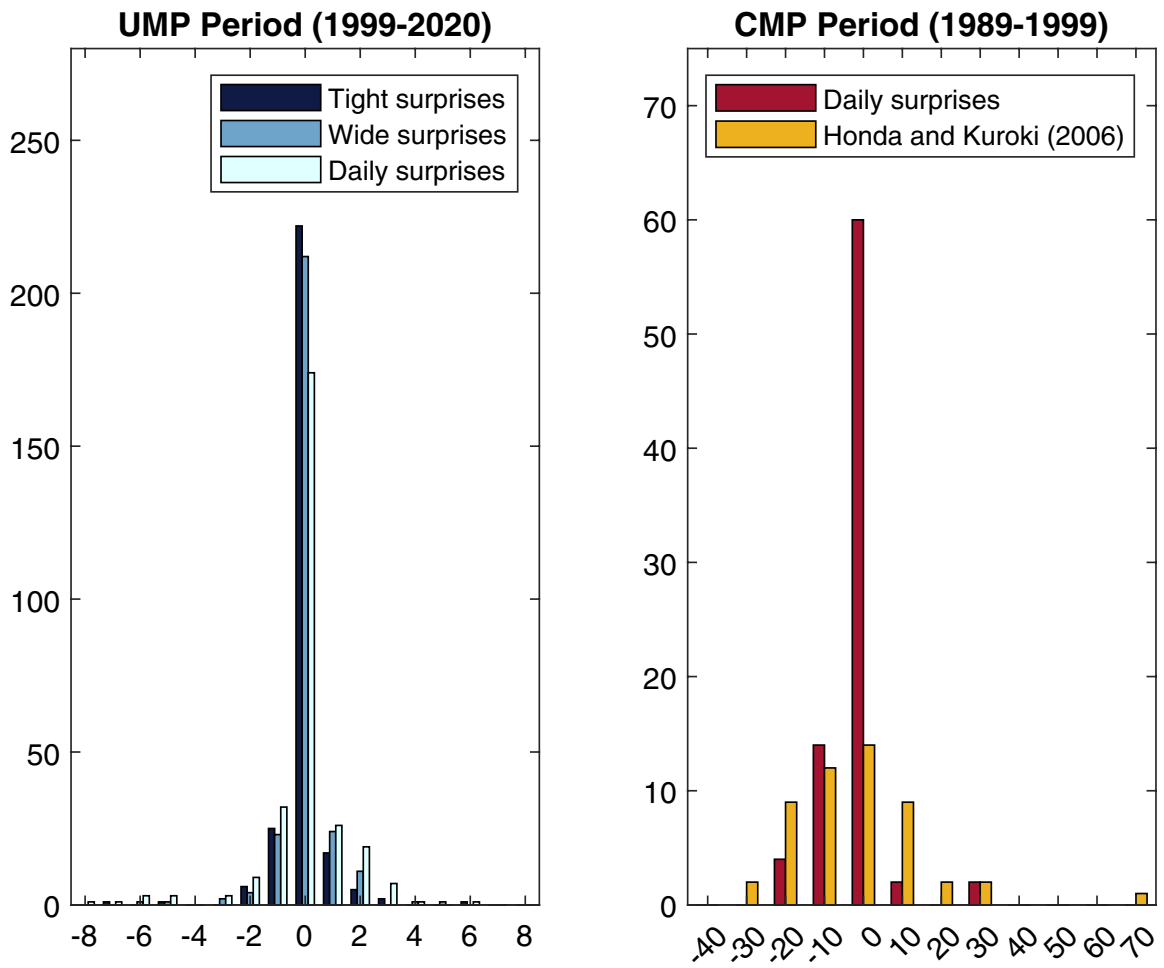

Fig. 2 Monetary policy surprises: empirical distribution. Note: "UMP Period" and "CMP Period" refer to the unconventional monetary policy and the unconventional monetary policy periods, respectively. The left panel shows the distributions of the three surprise series for the unconventional monetary policy period: the tight, wide, and daily EYF3 surprises around 280 press releases from October 13, 1999 through January 21, 2020. The right panel shows the distributions of the two surprise series for the conventional monetary policy period: the daily EYF3 surprises and the series of Honda and Kuroki (2006). The daily surprises are measured around 33 policy announcements from January 16, 1998 through January 21, 1999 and 49 policy changes from October 11, 1989 through November 28, 1997, while the original surprises of Honda and Kuroki (2006) are based on 51 policy changes from August 7, 1989 through September 10, 1998. The unit of the horizontal axis is a basis point

\section{Asset price and the monetary policy surprises}

\subsection{Event study regression on the surprises}

In this section, we evaluate the instantaneous effects of a monetary policy surprise on the asset market. In particular, we follow Gürkaynak et al. (2005) and run the regression of the form:

$$
\Delta y_{t}=\alpha+\beta \Delta x_{t}+\varepsilon_{t},
$$

where $\Delta y_{t}$ is the asset price change within some intervals; $\Delta x_{t}$ is the unanticipated change in the futures rate within the same interval; $\alpha$ and $\beta$ are a constant and a slope coefficient, respectively; and $\varepsilon_{t}$ is an error term. When the length of the interval is 

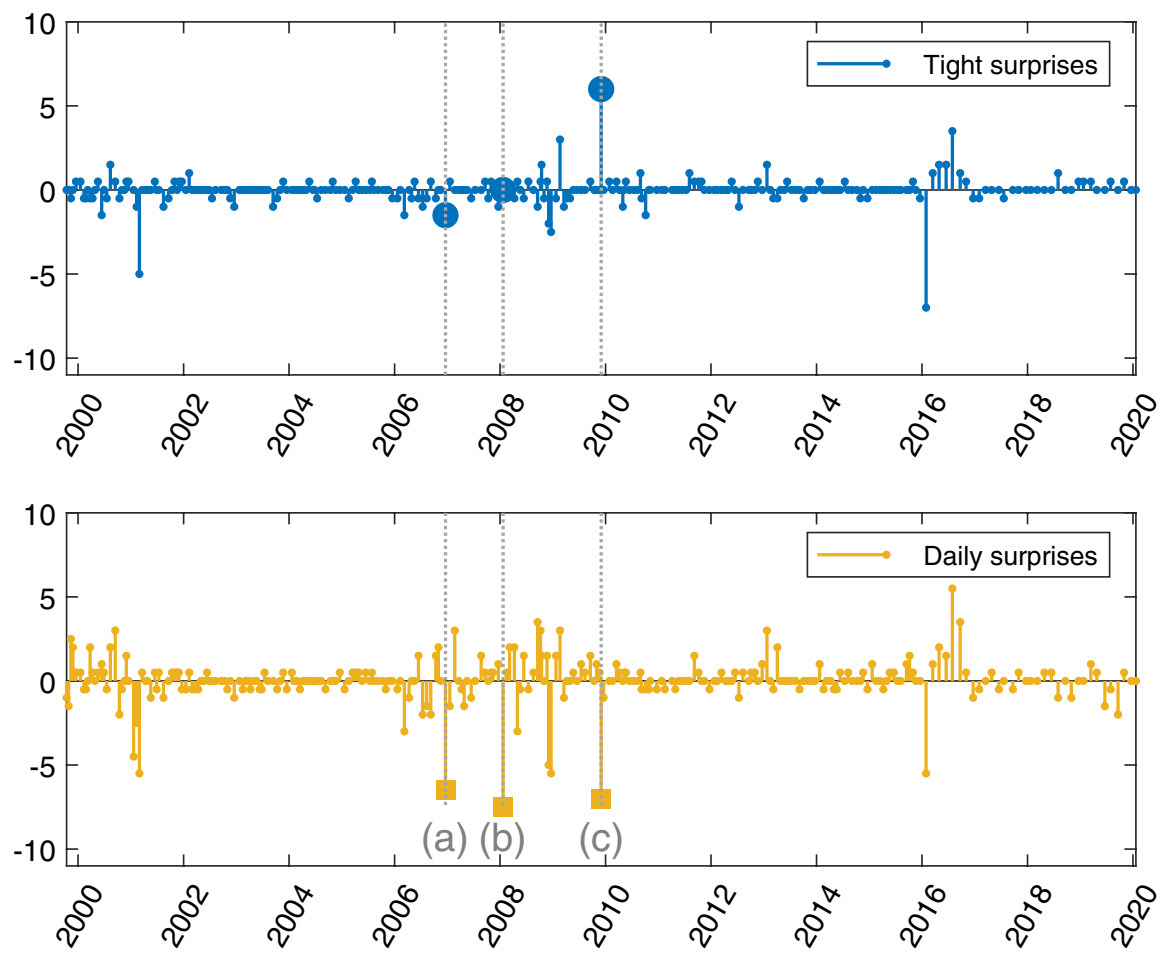

Fig. 3 Monetary policy surprises: time series plot. Note: The top panel and the bottom panel show the values of tight surprises and daily surprises for the 3-month ahead Euroyen futures rate (basis points), respectively. a-c marked in the figure indicates December 19, 2006, January 22, 2008, and December 1, 2009 , respectively. The sizes of surprises on the three dates are indicated by circles in the top panel and squares in the bottom panel

long, $\Delta x_{t}$ in (1) is likely to be endogenous, because (i) the monetary policy could react to movements in the financial market, or (ii) there could be a possible confounding variable affecting both the monetary policy and the financial market. However, as discussed in Gürkaynak et al. (2005), when the interval is sufficiently short, $\Delta x_{t}$ can be treated as an exogenous variable, because the monetary policy decision is less likely to respond to asset price movements and the possibility of the confounder can be excluded. We use high-frequency data for stock price indexes and the government bond yields to construct dependent variables $\Delta y_{t}$, namely, changes in asset prices within the same windows as those used to construct $\Delta x_{t}$. For the stock price index, we measure percent changes in the Tokyo Stock Price Index (TOPIX) and Nikkei 225. For the government bonds, we take differences in the 1-, 2-, 5-, 10-, and 20-year JGB yields. In what follows, we refer each of the JGB yields to JGB1Y, JGB2Y, JGB5Y, JGB10Y, and JGB20Y, respectively. ${ }^{16}$ As noted before, our sample

${ }^{16}$ See Appendix A for the data sources. 
(a) December 19, 2006 (March 2007 Contract)

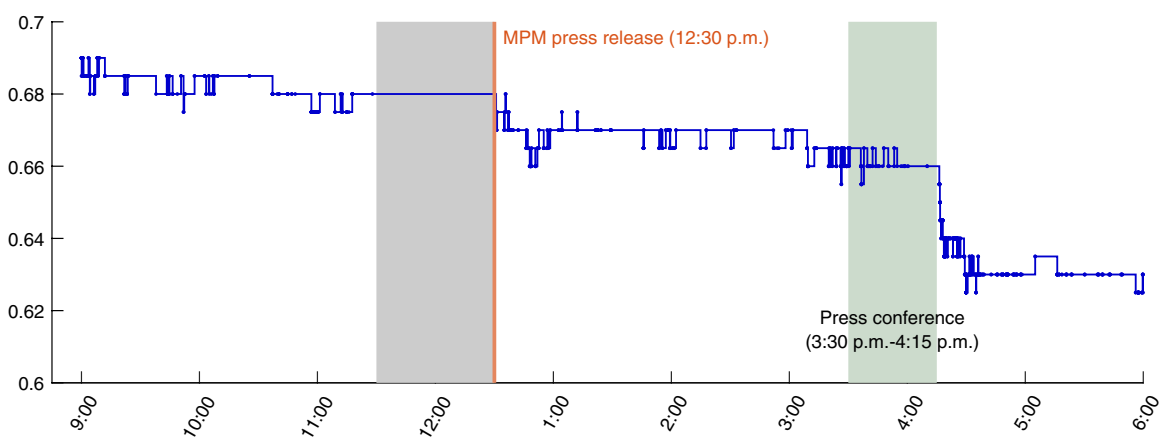

(b) January 22, 2008 (March 2008 Contract)

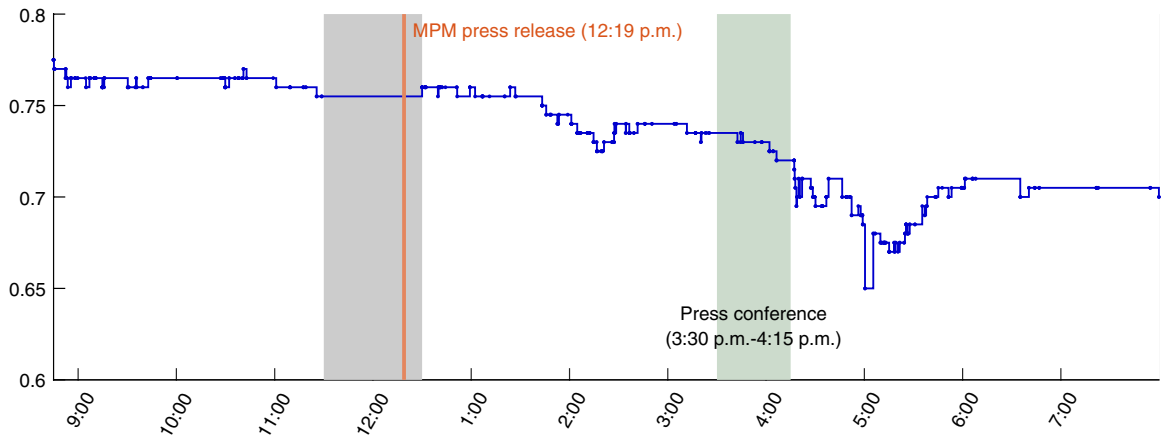

(c) December 1, 2009 (March 2010 Contract)

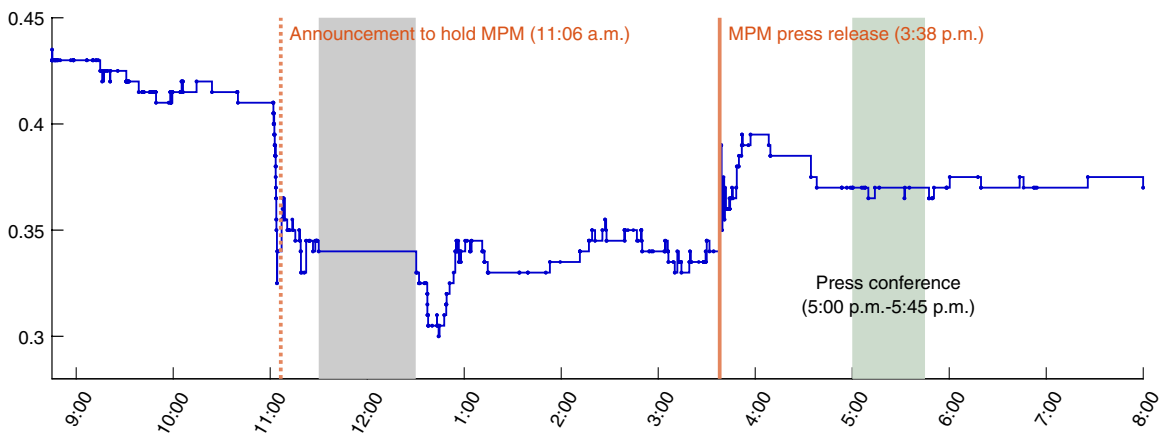

Fig. 4 Intraday changes in Euroyen futures rate (2). Note: Panels a-c show the 3-month ahead Euroyen futures rates (percentage) on the three selected MPM dates: December 19, 2006, January 22, 2008, and December 1, 2009. The times of the press releases are indicated by the vertical lines for every panel, and the time of the announcement to hold the unscheduled MPM is indicated by the dotted vertical line only for panel $\mathbf{c}$, which is the date of the unscheduled MPM. The darker shaded area indicates the lunch break for the Euroyen futures market (11:30 a.m.-12:30 p.m.), and the lighter shaded area indicates the press conference for the explanation of the policy decisions in the MPM. Since the precise times of the announcements to hold the unscheduled MPMs are not made public by the BOJ, the time at which the first news flash bulletin about holding the unscheduled MPMs was released in Bloomberg is indicated 
contains 280 MPMs held in the period from October 13, 1999 through January 21, 2020, after excluding the four selected MPMs.

Table 1 reports the simple regression results when our tight surprise series, namely, EYF3, EYF6, EYF9, EYF12, and JGBF, are used as regressor $\Delta x_{t}$. For each regression, the estimate of $\beta$, its standard error, and $R^{2}$ are reported. When two stock price indexes, namely, Nikkei 225 and TOPIX, are used as $\Delta y_{t}$, and are regressed on EYF surprises, all the coefficients are negative and statistically significant. For the regression on JGBF surprises, the coefficients are also negative while not statistically significant. Since a surprise in a positive direction, namely, a contractionary monetary policy shock, is expected to result in a decline in the stock prices, our results are consistent with the standard theoretical prediction. When the government bond yields are used as $\Delta y_{t}$, coefficients are positive and statistically significant in all the cases. These observations are also consistent with the theoretical prediction, because a contractionary monetary policy shock is likely to raise the interest rates of various maturities.

In the case of EYF3, for example, the Nikkei 225 and TOPIX decline by approximately 15 and $10 \%$, respectively, in response to an unanticipated 1 percentage point monetary policy tightening. Both estimates are much larger than those of Gürkaynak et al. (2005), who estimate a $4 \%$ decline. In our view, this outcome partly reflects the fact that the size of EYF surprises becomes much smaller for the unconventional monetary policy period, compared to the conventional monetary policy period as we observed in Fig. 2. When the government bond yield is used as a dependent variable, the 1-year JGB yield instantly increases by 11.8 basis points in response to an EYF3 surprise. As the maturity becomes longer, the size of the coefficient increases monotonically up to 10 years, and the response is the largest for the 10-year JGB yield, which could be viewed as an implicit policy target of the Bank of Japan throughout most of our sample period. This outcome differs from the previous studies of the conventional monetary policy period obtained in Gürkaynak et al. (2005) for the US and Honda and Kuroki (2006) for Japan, where the size of the coefficient decreases with the maturity. At the same time, our results are in line with Swanson (2021), who finds that "forward guidance" and "LSAP" factors tend to play a larger role for the longer term rates in the US.

The results of the estimated coefficients are similar for the other EYF surprise series. These findings suggest that expectations at horizons longer than 3 months are as important as the 3-month ahead expectations contained in EYF3, at least up to a 1-year horizon. This interpretation motivates us to extract the information efficiently from all the four EYF surprise series by using factor analysis in Sect. 4. Since coefficients on the JGBF surprises are not statistically significant in stock price regression, we first focus on the EYF surprises and then examine the effect of adding the JGBF surprises later in Sect. 5.

\subsection{Regression using alternative windows}

Let us now consider the possibility of using different windows when running the regression of asset price changes on EYF3 surprises. Table 2 shows the results from 


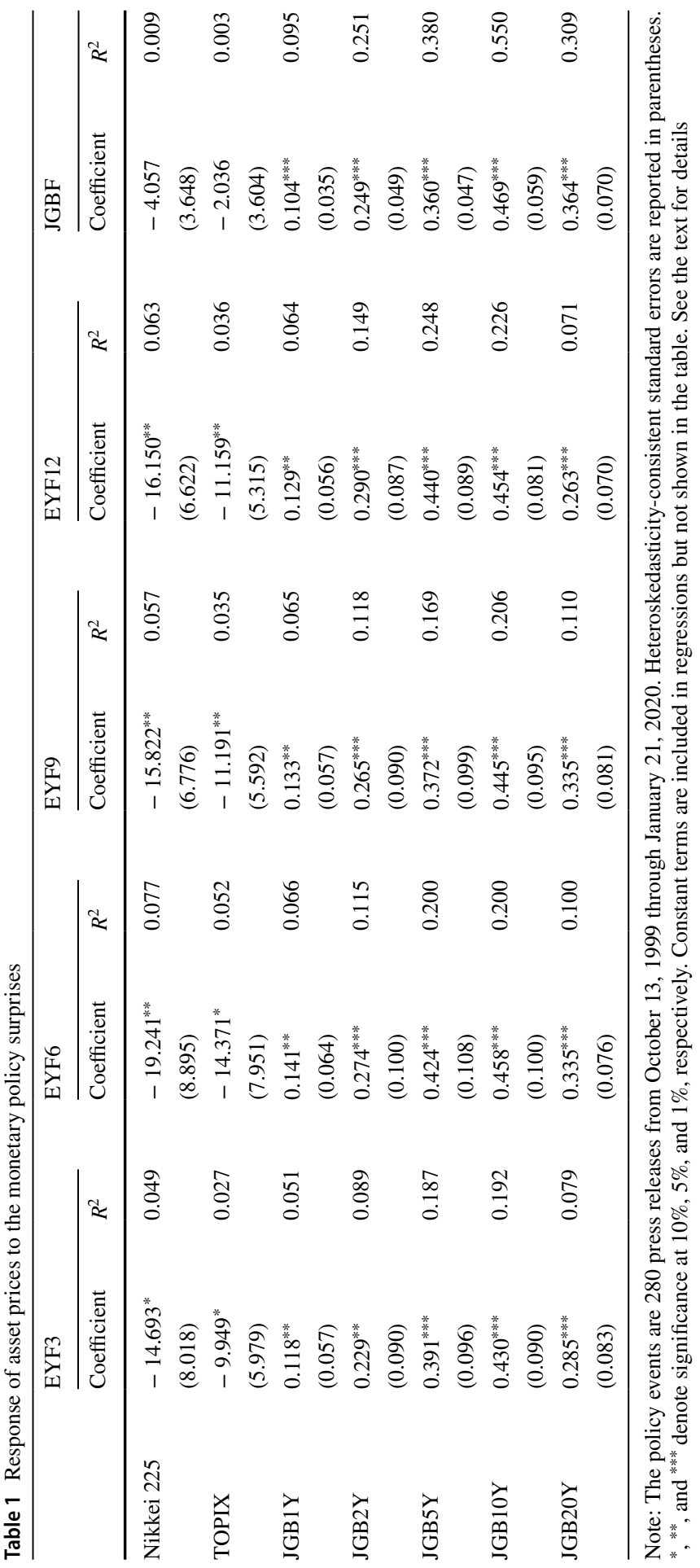


Table 2 Response of asset prices to the EYF3 surprises

\begin{tabular}{|c|c|c|c|c|c|c|}
\hline & \multicolumn{2}{|c|}{ EYF3 (tight window) } & \multicolumn{2}{|c|}{ EYF3 (wide window) } & \multicolumn{2}{|c|}{ EYF3 (daily window) } \\
\hline & Coefficient & $R^{2}$ & Coefficient & $R^{2}$ & Coefficient & $R^{2}$ \\
\hline Nikkei 225 & $\begin{array}{l}-14.693^{*} \\
(8.018)\end{array}$ & 0.049 & $\begin{array}{l}-6.123 \\
(5.483)\end{array}$ & 0.007 & $\begin{array}{l}15.339 \\
(9.904)\end{array}$ & 0.023 \\
\hline TOPIX & $\begin{array}{l}-9.949^{*} \\
(5.979)\end{array}$ & 0.027 & $\begin{array}{l}-2.617 \\
(5.209)\end{array}$ & 0.002 & $\begin{array}{l}15.044 \\
(9.222)\end{array}$ & 0.028 \\
\hline JGB1Y & $\begin{array}{l}0.118^{* *} \\
(0.057)\end{array}$ & 0.051 & $\begin{array}{l}0.146 \\
(0.104)\end{array}$ & 0.050 & $\begin{array}{l}0.462^{* * *} \\
(0.103)\end{array}$ & 0.262 \\
\hline JGB2Y & $\begin{array}{l}0.229^{* *} \\
(0.090)\end{array}$ & 0.089 & $\begin{array}{l}0.426^{* *} \\
(0.166)\end{array}$ & 0.135 & $\begin{array}{l}0.560^{* * *} \\
(0.100)\end{array}$ & 0.272 \\
\hline JGB5Y & $\begin{array}{l}0.391^{\text {*** }} \\
(0.096)\end{array}$ & 0.187 & $\begin{array}{l}0.385^{* *} \\
(0.183)\end{array}$ & 0.111 & $\begin{array}{l}0.724^{* * *} \\
(0.121)\end{array}$ & 0.237 \\
\hline JGB10Y & $\begin{array}{l}0.430^{* * *} \\
(0.090)\end{array}$ & 0.192 & $\begin{array}{l}0.639^{* * *} \\
(0.211)\end{array}$ & 0.209 & $\begin{array}{l}0.737^{* * *} \\
(0.144)\end{array}$ & 0.153 \\
\hline JGB20Y & $\begin{array}{l}0.285^{* * *} \\
(0.083)\end{array}$ & 0.079 & $\begin{array}{l}0.516^{* * *} \\
(0.161)\end{array}$ & 0.138 & $\begin{array}{l}0.625^{* * *} \\
(0.157)\end{array}$ & 0.056 \\
\hline
\end{tabular}

Note: The dependent variable is the EYF3 surprises within each window. The policy events are 280 press releases from October 13, 1999 through January 21, 2020. Heteroskedasticity-consistent standard errors are reported in parentheses. ${ }^{*},{ }^{* *}$, and ${ }^{* * *}$ denote significance at $10 \%, 5 \%$, and $1 \%$, respectively. Constant terms are included in regressions but not shown in the table

the regression on the EYF3 surprises using the wide and daily windows along with the results using the tight window, which are already provided in Table 1. Figures 5 and 6 show the scatterplots for selected regression results to display the effect of choosing different windows.

The table and figures suggest that effects on the stock prices become ambiguous when wider windows are used to measure the surprises. The estimated coefficients are not significantly different from zero, even with the $10 \%$ significance level for a wide window. Furthermore, when a daily window is used, the estimated coefficient becomes positive, which is against the standard theoretical predictions. Regarding the effects on the JGB yields, estimated coefficients tend be larger when the window becomes wider. However, the coefficient becomes insignificant in the case of 1-year JGB yield when a wide window is used.

These results support the claim by Gürkaynak et al. (2005) that the 30-min window is useful for the purpose of identifying the pure monetary policy surprises by eliminating the effects of other shocks. 
Nikkei 225

Tight Window

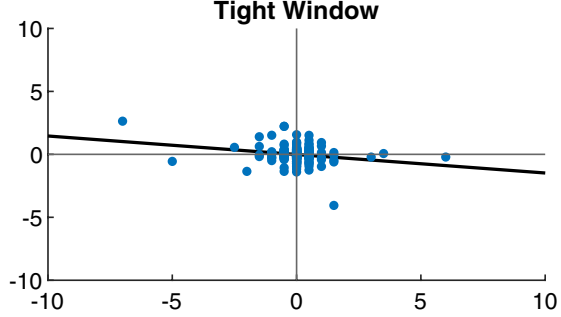

Wide Window
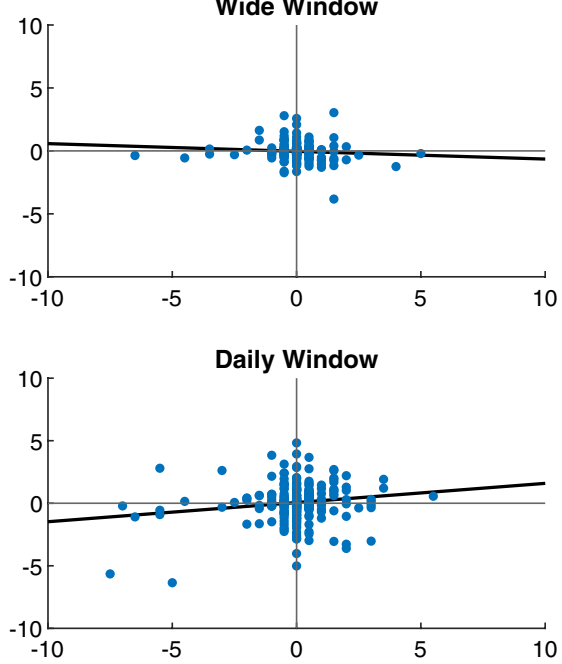

TOPIX

Tight Window

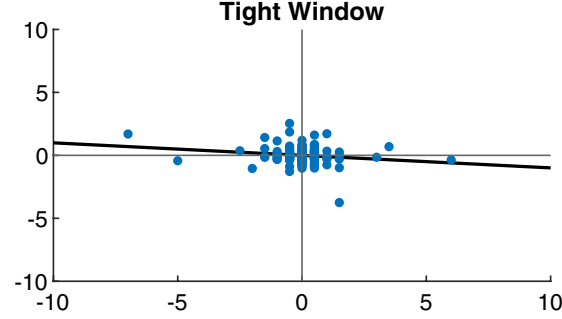

Wide Window

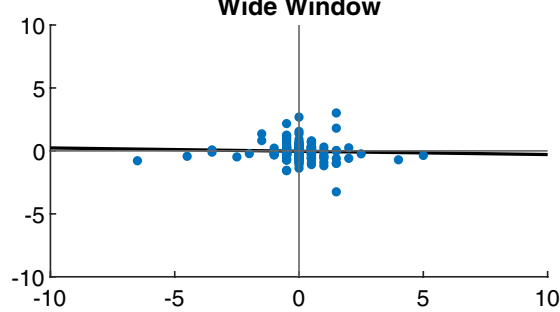

Daily Window

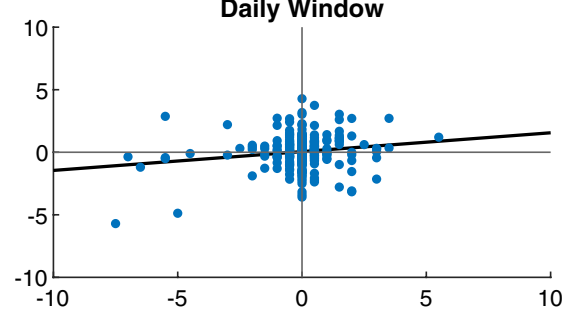

Fig. 5 Responses of the stock prices to the monetary policy surprises: Euroyen futures. Note: The top two panels, the middle two panels, and the bottom two panels plot the EYF3 surprises (horizontal axes) and the percent changes in the stock prices (vertical axes) based on a tight window, a wide window, and a daily window, respectively. The left-side panels show the case when the percent change in the Nikkei 225 is on vertical axes, and the right-side panels show the case when the percent change in the TOPIX is on vertical axes. The unit of the horizontal axes is a basis point. Each point represents the surprise and stock price change for a day of MPM. Crosses indicate the pairs of values on December 1, 2009. The leastsquares fitted lines are also shown

\section{Asset price responses to the target and path factors}

\subsection{Identification of the target and path factors}

When multiple series of surprise measures are available, it is often convenient to summarize the information in terms of the common factors in the factor model framework. For example, for the US monetary policy surprises, Gürkaynak et al. (2005) find the presence of two important common factors, while Swanson (2021) claims three common factors. In the case of Japan, Nakashima et al. (2020) identify three common factors in monetary policy surprises. 

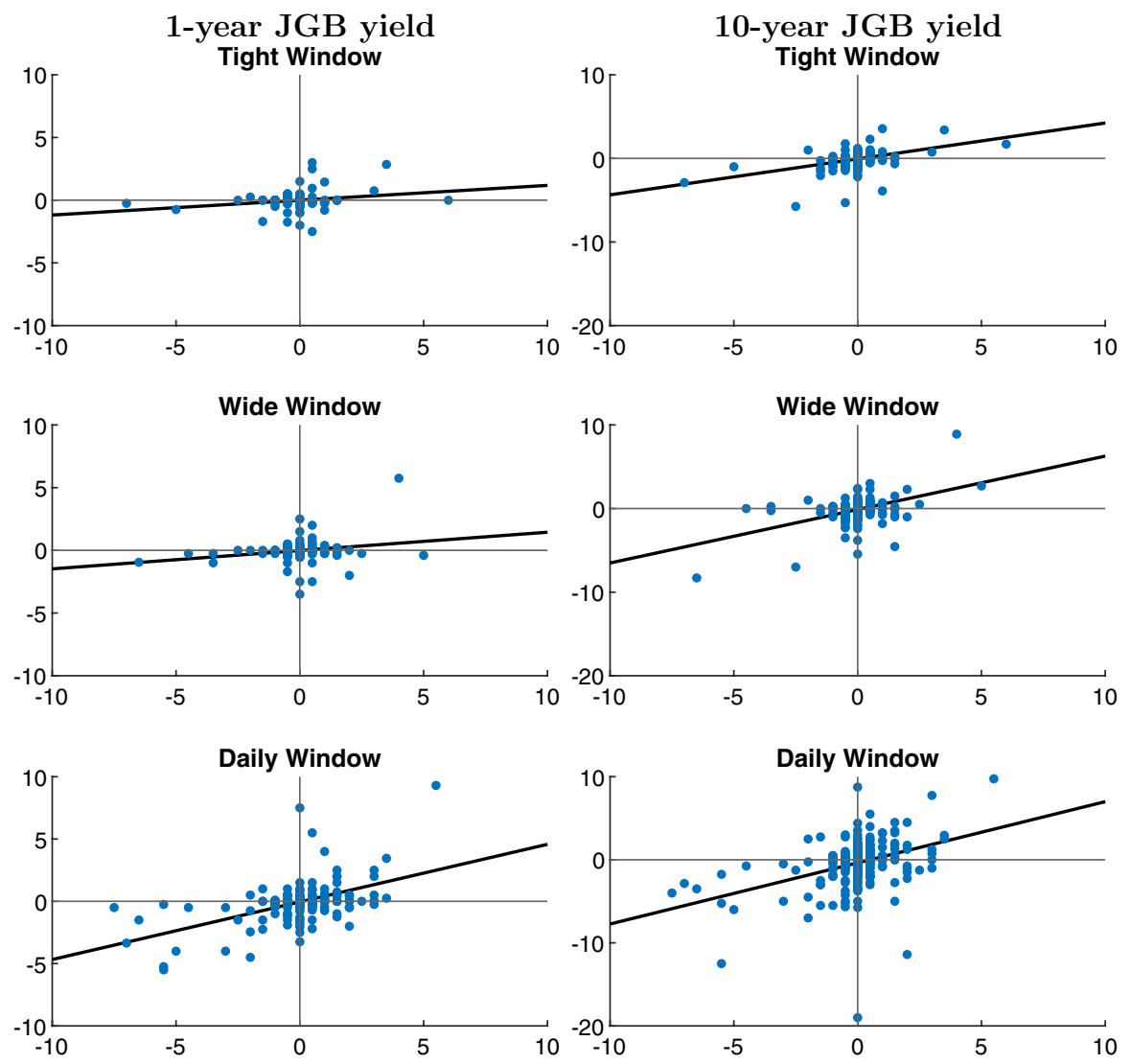

Fig. 6 Responses of the JGB yields to the monetary policy surprises: Euroyen futures. Note: The top two panels, the middle two panels, and the bottom two panels plot the EYF3 surprises (horizontal axes) and the JGB yield changes (vertical axes) based on a tight window, a wide window, and a daily window, respectively. The left-side panels show the case when the 1-year JGB yield change is on vertical axes and the right-side panels show the case when the 10-year JGB yield change is on vertical axes. The unit of the axes is a basis point. Each point represents the surprise and JGB yield change for a day of MPM. Crosses indicate the pairs of values on December 1, 2009. The least-squares fitted lines are also shown

We begin our factor analysis by focusing on EYF surprises, based on the fact that negative and statistically significant coefficients on the EYF surprises in the stock price regression in Table 1 are consistent with a standard theory. The rank test statistics of Cragg and Donald (1997) for the null hypotheses of the number of factors being zero and one are 28.480 and 6.397, respectively. Since both the no factor and one factor hypotheses are rejected at the $5 \%$ level in favor of two factors, in what follows, we proceed with the analysis of two factors. ${ }^{17}$

\footnotetext{
${ }^{17}$ Under the null hypotheses of no factor and one factor, the rank test statistics asymptotically follow the $\chi^{2}$ distribution with 6 and 1 degrees of freedom, respectively. Unlike Gürkaynak et al. (2005), we cannot conduct a test for the null hypothesis of two factors, because the corresponding test statistic degenerates when the number of variables is 4 .
} 
We employ the identification strategy of Gürkaynak et al. (2005) and assume one factor, which they called the path factor, has zero impact on the nearest futures rate, EYF3 surprises. The other factor, which is orthogonal to the path factor, is called the target factor. Let $T$ denote the sample size and $X=\left[X_{E Y F 3} X_{E Y F 6} X_{E Y F 9} X_{E Y F 12}\right]$ be a $T \times 4$ matrix, which consists of column vectors of the four EYF surprise series. Typically, $F$, which is a $T \times 2$ matrix of the first and second principal components of $X$ in the common factor model $X=F \Lambda^{\prime}+\eta$, is obtained by imposing the restrictions $F^{\prime} F / T=I_{2}$ and $\Lambda^{\prime} \Lambda=D$, where $D$ is a $2 \times 2$ diagonal matrix, $\Lambda$ is a $4 \times 2$ matrix of the factor loadings and $\eta$ is a $T \times 4$ matrix of idiosyncratic error terms. Let $Z_{\text {Target }}$ and $Z_{\text {Path }}$ be the $T \times 1$ vectors of the target and path factors, respectively. The matrix of identified factors $\left[Z_{\text {Target }} Z_{\text {Path }}\right]=F U$ is obtained by rotating $F$ with a $2 \times 2$ rotation matrix $U$, which satisfies $U^{\prime} U=U U^{\prime}=I_{2}$. This rotation matrix can be found by imposing the zero restriction on the $(1,2)$ element of the $4 \times 2$ matrix of the rotated factor loadings $\Lambda U$, so that the path factor has zero effect on EYF3 surprises.

It can intuitively be discerned that the target factor affects the 3-month ahead expectations as well as longer horizon expectations, while the path factor affects only the more-than-6-month ahead expectations. In this sense, our target and path factors reflect the relatively short- and long-term expectations on the interest rate, respectively. It should be noted that our target factor differs from the target factor of Gürkaynak et al. (2005) for the following reasons. First, while they use futures contracts for the overnight rate, we use those for the 3-month interest rate. Second, the shortest remaining maturity of the futures is 1 month in their study, but is 3 months in our analysis. These two differences suggest that our target factor captures surprises in the relatively longer term expectations than their target factor does. Finally, our target factor does not correspond to the surprises in the policy target of Bank of Japan, while their target factor matches the target of Federal Reserve Board. For the sake of convenience, however, we keep using the terms, the target, and path factors, because our identifying restriction on the factor loading matrix is exactly the same as that of Gürkaynak et al. (2005).

Figure 7 plots our estimated target factor and path factor from four EYF surprise series from October 13, 1999 to January 21, 2020. For instance, on January 29, 2016, the target factor takes a large and negative value of -0.059 , while the path factor is nearly zero. This observation implies that the introduction of the negative interest rate policy on that day mainly affects the relatively short horizon expectations.

\subsection{Event study regression on the factors}

We now turn to investigate the effects of the estimated factors on stock prices and the JGB yields. We replace a single surprise measure $\Delta x_{t}$ in regression (1) by the two factors, namely, the target factor $Z_{\text {Target }, t}$ and path factor $Z_{\mathrm{Path}, t}$ and run the regression of the form:

$$
\Delta y_{t}=\alpha+\beta Z_{\text {Target }, t}+\gamma Z_{\mathrm{Path}, t}+\varepsilon_{t} .
$$


The sample period and the dependent variables are the same as those used in regression (1).

Table 3 shows the coefficient estimates and coefficients of determination from (2) using the tight, wide, and daily windows. The regression coefficients reported in the table are rescaled, so that the positive sign corresponds to tightening surprises based on the EYF surprise series. ${ }^{18}$ On the whole, our results in the table show the importance of the two factors in characterizing the monetary policy shocks in Japan. In particular, the use of a tight window, rather than the wide and daily windows, helps us to capture the role of each factor. Our main findings from this analysis can be summarized in the following two points.

First, in the case of the 30-min window, both the target and path factors have significant effects on asset prices in almost all the instances. The significant effects of the path factor imply the role of monetary policy in changing the longer term horizon expectations. The only exception is the TOPIX regression, in which the response to the path factor is negative but insignificant. In response to a 1 percentage point increase in the target factor, the Nikkei 225 declines by more than $16 \%$ and the 1-year JGB yield increases by 13.0 basis points. On the other hand, in response to a 1 percentage point increase in the path factor, the Nikkei 225 declines by about $8.6 \%$ and the 1-year JGB yield rises by 7.4 basis points. Negative coefficients in the stock price regression and positive coefficients in the government bond yield regression are consistent with the theoretical prediction. The directions of responses in our regressions are also consistent with the results obtained by Gürkaynak et al. (2005), while our estimated responses of stock prices are much larger than their estimates for the conventional monetary policy period in the US. The larger responses in our analysis may be explained by relatively smaller variations in interest rates due to the ZLB. It should also be noted that the selection of the 30-min window is not only important in the analysis using single Euroyen futures surprises but also that using multiple factors. Similar to the results in Table 2, estimated coefficients on two factors in the stock price regression become statistically insignificant in the case of the wide window, and the sign of the responses becomes positive in the case of the daily window.

Second, we observe that the responses of JGB yields tend to be larger for the longer term yields and smaller for the shorter term yields. While the response of the 1-year JGB yield is as small as 13.0 basis points for the target factor and 7.4 basis points for the path factor, the size of the response becomes larger for the longer term rates. The size of the response increases with the maturity and becomes largest around 10 years. The response of the 10-year JGB yield is 44.9 basis points for the target factor and 24.7 basis points for the path factor. Again, this finding is in contrast to the results in Gürkaynak et al. (2005) and Honda and Kuroki (2006), who study the conventional monetary policy in the US and in Japan, respectively, and find that the responses are smaller for longer term rates. In our view, this difference

\footnotetext{
18 Specifically, the scales of the factors are normalized, so that the coefficient on the target factor in the regression of EYF3 is one, and the coefficient on the path factor in the regression of EYF12 is the same as that on the target factor.
} 

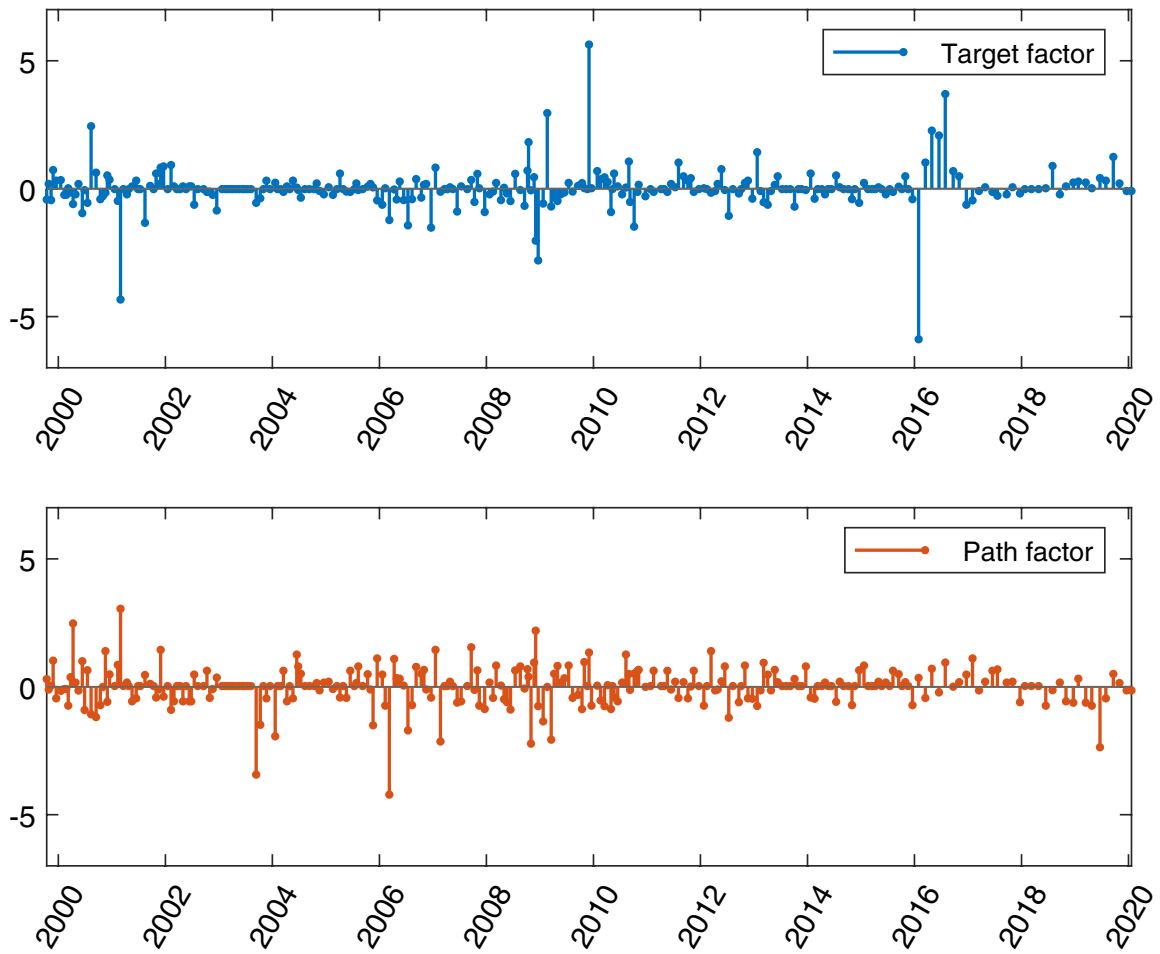

Fig. 7 The target factor and path factor: time series plot. Note: The top panel plots the target factor and the bottom panel plots the path factor. The factors are estimated from the four Euroyen futures surprise series. The policy events are 280 press releases from October 13, 1999 through January 21, 2020. See the text for details

is caused by the ZLB, which is less likely to constrain the long end of the yield curve. As noted in the previous section, our finding is in line with that of Swanson (2021), who finds that the effects of forward guidance and bond purchases are larger for the long-term rates. ${ }^{19}$

The finding of larger responses of longer term yields is consistent with the view that monetary policy results in the flattening yield curve under the ZLB. In general, a shift of the yield curve can be caused by monetary policy surprises. However, since shorter term rates are likely to be constrained at near zero in Japan, there is more room for the long end of the yield curve to shift. Recall that, among the longer term yields, the response of the 10-year JGB yield is the largest, which is effectively targeted by the BOJ. At the time when the Yield Curve Control (YCC) policy was introduced, the BOJ announced, in the statement released after the MPM on September 21, 2016, that "The Bank will purchase Japanese government bonds (JGBs) so that 10-year JGB yields will remain more or less at the current level." Long before

\footnotetext{
19 Our finding is also consistent with Koeda (2017) who finds that the risk premium is barely affected by the bond purchases in the short end of the yield curve when the ZLB binds.
} 


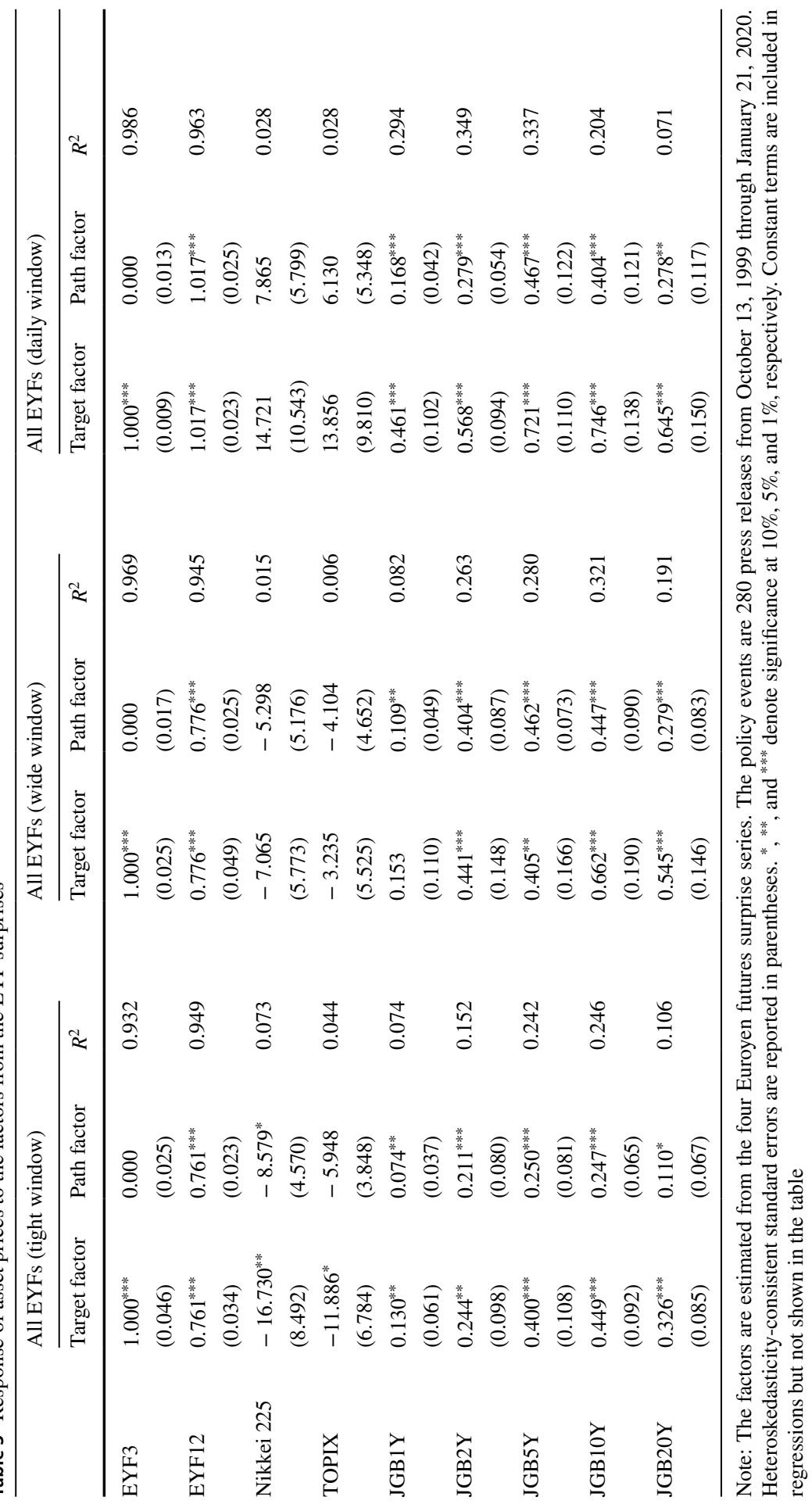


the introduction of $\mathrm{YCC}$, the BOJ has been purchasing the long-term government bonds as a policy instrument. ${ }^{20}$ In this sense, the long-term rate can be considered as an implicit policy target of the BOJ. Thus, our results suggest that the BOJ has been successful in controlling the long-run expectations by MPM announcements.

\section{Robustness checks}

\subsection{Press conferences and unscheduled meetings}

So far, we have focused on surprises around the press releases of the MPM statements as a baseline in measuring the monetary policy shocks. We can extend the analysis to incorporate other events associated with the MPMs; namely, the postMPM press conferences and the announcement to hold the unscheduled meetings.

We first consider the possibility of monetary policy surprises from the press conferences. ${ }^{21}$ In the post-MPM press conferences, the governor of the BOJ explains the policy decision in the MPM, along with prospects of the policy stance and the economy. ${ }^{22}$ Thus, the post-MPM press conferences are directly associated with the MPM and may change the market expectations in a way that is different from the MPM press releases. One such example is provided in panel (a) of Fig. 4. For this reason, we measure the tight surprise around the post-MPM press conferences as well as the MPM press releases, and estimate the target and path factors. ${ }^{23} \mathrm{We}$ measure the surprises within a window from 10 min before the beginning of the press conference to $20 \mathrm{~min}$ after the end of the press conference. The left panel of Table 4 presents the estimation results when the 230 post-MPM press conferences during our sample period are included as additional events in the event study regression of asset prices on the target and path factors. On the whole, the estimation results in the left panel of Table 4 are consistent with our main findings in Table 3 with respect to the sign of estimated coefficients, while the responses of Nikkei 225 and the 1-year JGB yield to the path factor become statistically insignificant.

Second, we further consider the issue of the unscheduled meetings. The news alone of holding the unscheduled meeting can change market expectations, because the market participants may anticipate that some policy changes will be made in such a meeting. For example, as shown in panel (c) of Fig. 4, on December 1, 2009, there were three types of events in a single day, namely, the announcement to hold the unscheduled MPM at 11:06 a.m., the MPM press release at 3:38 p.m., and the

\footnotetext{
20 The BOJ had purchased the long-term government bonds even before adopting the zero-interest rate policy in 1999. This fact is explained in the statement released after the MPM on February 12, 1999. The pace of the purchases had been gradually increased and arrived at 80 trillion yen per year in 2014 .

21 Altavilla et al. (2019) and Cieslak and Schrimpf (2019) also emphasize the importance of the FOMC press conferences and conduct the event study using press conferences as the monetary policy event in the US.

22 The governor's press conference has been held the same day of an MPM since October 10, 2003. Before then, it was held once a month, 2 days after the first MPM in the month.

23 Based on the Cragg and Donald (1997) test, the null hypotheses of no factor and one factor are rejected at the $5 \%$ level in favor of two factors.
} 
post-MPM press conference from 5:00 p.m. The figure suggests that, in addition to the press release, the market's expectations could be affected by the announcement to hold the unscheduled MPM.

To consider such a possibility, we include six announcements to hold the unscheduled MPMs as the additional monetary policy events. The dates and times of the announcements to hold and the press releases of the statements for all the unscheduled meetings are summarized in Table 5. As shown in the table, announcements to hold the unscheduled meetings are made for six out of the nine unscheduled meetings within our sample period. For these six meetings, we additionally measure the policy surprises within a window from 10 min before the announcements to hold the unscheduled meetings to 20 min after that. Using the combination of surprises around the press releases and those around the announcements to hold unscheduled meetings, we estimate the target and path factors. ${ }^{24}$ We report the results of the event study regressions in the right panel of Table 4. Again, the estimation results are consistent with our main findings in Table 3, with respect to the sign of estimated coefficients. The response of TOPIX to the path factor becomes statistically significant at the $5 \%$ level, while that of the 20 -year JGB yield to the path factor becomes statistically insignificant.

\subsection{Surprises in the 10-year government bond futures}

In this subsection, we use the JGBF surprises in estimating factors to incorporate the changes in expectations on the long-term interest rates along with the EYF surprises, which reflect the changes in expectations on the short-term interest rate. While the stock price responses to the JGBF surprises are statistically insignificant in Table 1, the JGBF surprises possibly contain information that would be useful in capturing the effects of monetary policy during the period when the BOJ has effectively targeted the 10-year JGB yield. For the path factor to reflect the changes in the expected long-term rate in an appropriate way, we again follow Gürkaynak et al. (2005) and assume that the path factor has zero effect on EYF3 surprises. To obtain the target and path factors, we now rotate the first and second principal components of a $T \times 5$ matrix $X=\left[X_{E Y F 3} X_{E Y F 6} X_{E Y F 9} X_{E Y F 12} X_{J G B F}\right]$, where $X_{J G B F}$ represents the JGBF surprise series, such that the $(1,2)$ element of the $5 \times 2$ matrix of the factor loadings $\Lambda U$ is restricted to be zero in the common factor model $X=F \Lambda^{\prime}+\eta{ }^{25}$

\footnotetext{
${ }^{24}$ Based on the Cragg and Donald (1997) test, the null hypotheses of no factor and one factor are rejected at the $5 \%$ level in favor of two factors.

${ }^{25}$ The rank test of Cragg and Donald (1997) suggests that the null hypothesis of one factor model cannot be rejected at the $5 \%$ level. At the same time, the relative contribution of the first and the second principal components to the total variation are $76.6 \%$ and $11.2 \%$, respectively. Since $80 \%$ of the total variations has been used as a rule-of-thumb to select the number of common factors in the principal components analysis, we proceed with the analysis, assuming the presence of two factors.
} 


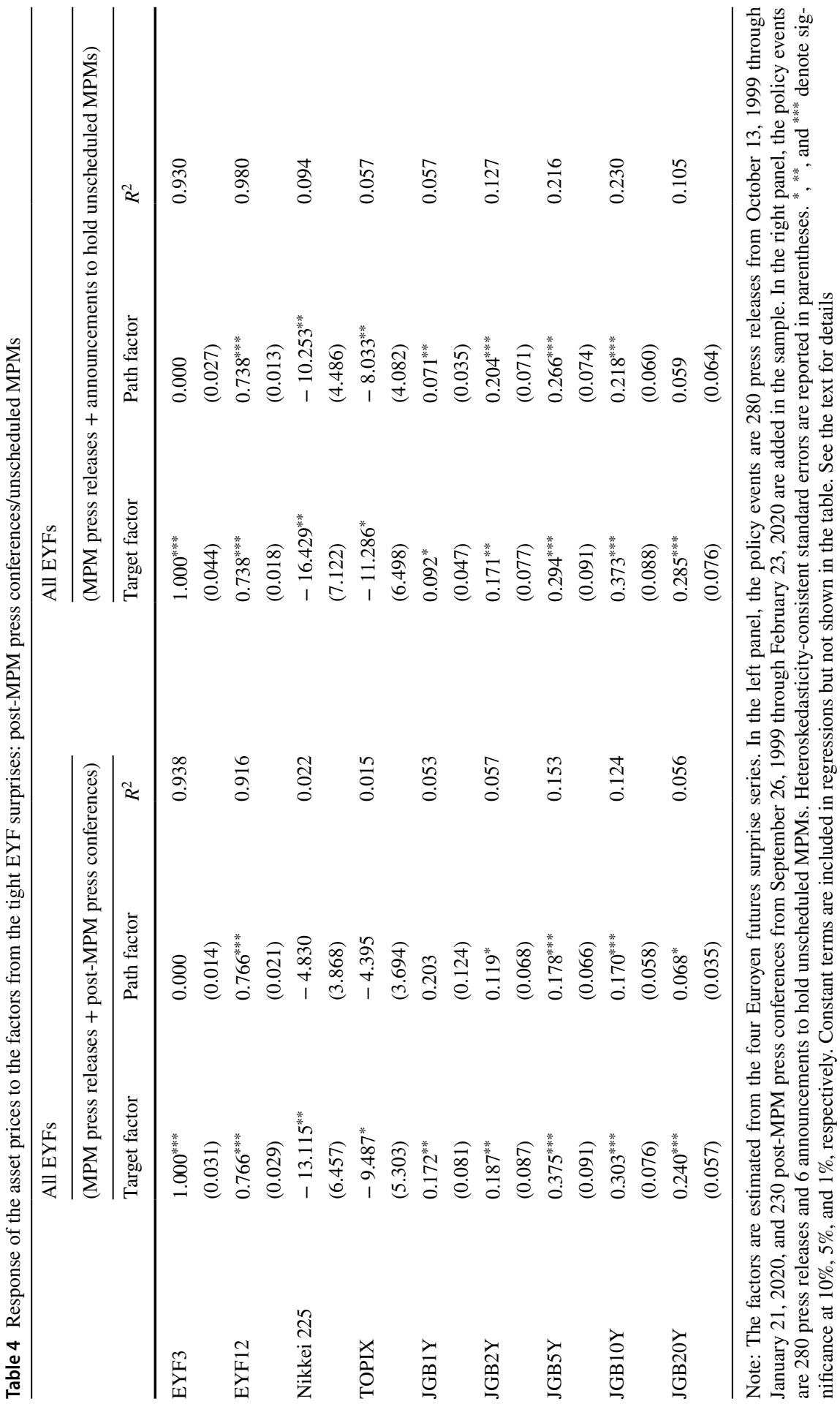


Table 5 Unscheduled MPMs between October 1999 and January 2020

\begin{tabular}{lll}
\hline Date & Announcement to hold & Press release \\
\hline March 25, 2003 & 3:40 p.m. on 24th & 11:55 a.m. \\
September 18, 2008 & NA & 4:00 p.m. \\
September 29, 2008 & NA & 11:00 p.m. \\
October 14, 2008 & 4:04 p.m. & $9: 38$ p.m. \\
December 2, 2008 & 5:30 p.m. on 1st & $2: 34$ p.m. \\
December 1, 2009 & 11:06 a.m. & $3: 38$ p.m. \\
May 10, 2010 & 10:40 a.m. & $12: 11$ p.m. \\
August 30, 2010 & 7:02 a.m. & $12: 11$ p.m. \\
November 30, 2011 & NA & $10: 00$ p.m. \\
\hline
\end{tabular}

Note: The list of unscheduled MPMs derives from the BOJ's past statements and minutes. As in Fig. 4, the precise times of the announcements to hold the unscheduled MPM refer to the news flash bulletins in Bloomberg. For the unscheduled MPMs on September 18, 2008, September 29, 2008, and November 30, 2011, the announcements to hold the meeting were not released. Also note that these three dates are excluded from our sample. See the text for details

We report the results of the event study regression in Table $6 .{ }^{26}$ As in the case where we use only the EYF surprises, the signs of the coefficients on the target factor are consistent with the theoretical predictions and also statistically significant. Regarding the coefficients on the path factor, two points differ from our previous results based on the EYF surprises only. First, we now have stronger evidence for the positive effect on the 20-year JGB yields, in the sense that the coefficient on the path factor becomes statistically significant at the $1 \%$ level. This outcome may reflect the fact that the JGBF surprises reflect changes in the longer horizon expectations. Second, in the stock price regression, the coefficients on the path factor become positive, while they are not statistically significant. The positive sign may suggest that the market participants learned the central bank's view on economic conditions in the long run, from the policy announcements.

In the literature of monetary policy, the channel of learning the central bank's view is often referred to as the central bank information effect. In fact, Gürkaynak et al. (2005) argue that the statistically insignificant coefficient on the path factor in their stock price regression was possibly caused by the information effect. To be more specific, the interest rate and the stock prices are likely to be shifted in the same direction by the information effect, while in the opposite direction by the monetary policy shock. Cieslak and Schrimpf (2019) and Jarociński and Karadi (2020) employ such a restriction to extract the information effect from the monetary policy

\footnotetext{
${ }^{26}$ We normalize the factors using a procedure similar to the one used in the previous section. The scales of the factors are normalized, so that the coefficient on the target factor in the regression of EYF3 is one, and the coefficient on the path factor in the regression of JGBF (not EYF12) is the same as that on the target factor.
} 
Table 6 Response of the asset prices to the factors from the tight EYF and JGBF surprises

\begin{tabular}{|c|c|c|c|}
\hline & \multicolumn{3}{|c|}{ All EYFs + JGBF } \\
\hline & $\overline{\text { Target factor }}$ & Path factor & $R^{2}$ \\
\hline EYF3 & $\begin{array}{l}1.000^{* * *} \\
(0.076)\end{array}$ & $\begin{array}{l}0.000 \\
(0.020)\end{array}$ & 0.833 \\
\hline JGBF & $\begin{array}{l}0.927^{* * *} \\
(0.016)\end{array}$ & $\begin{array}{l}0.927^{* * *} \\
(0.005)\end{array}$ & 0.995 \\
\hline Nikkei 225 & $\begin{array}{l}-19.879^{* *} \\
(8.674)\end{array}$ & $\begin{array}{l}2.947 \\
(3.874)\end{array}$ & 0.079 \\
\hline TOPIX & $\begin{array}{l}-14.212^{* *} \\
(7.037)\end{array}$ & $\begin{array}{l}3.247 \\
(4.056)\end{array}$ & 0.052 \\
\hline JGB1Y & $\begin{array}{l}0.145^{* *} \\
(0.065)\end{array}$ & $\begin{array}{l}0.076^{* * *} \\
(0.028)\end{array}$ & 0.105 \\
\hline JGB2Y & $\begin{array}{l}0.288^{* * *} \\
(0.086)\end{array}$ & $\begin{array}{l}0.210^{* * *} \\
(0.046)\end{array}$ & 0.262 \\
\hline JGB5Y & $\begin{array}{l}0.448^{* * *} \\
(0.090)\end{array}$ & $\begin{array}{l}0.287^{* * * *} \\
(0.046)\end{array}$ & 0.399 \\
\hline JGB10Y & $\begin{array}{l}0.481^{* * *} \\
(0.058)\end{array}$ & $\begin{array}{l}0.414^{* * *} \\
(0.068)\end{array}$ & 0.549 \\
\hline JGB20Y & $\begin{array}{l}0.322^{* * *} \\
(0.057)\end{array}$ & $\begin{array}{l}0.339^{* * *} \\
(0.085)\end{array}$ & 0.303 \\
\hline
\end{tabular}

Note: The factors are estimated from the four Euroyen futures surprise series and the JGB futures surprise series. The policy events are 280 press releases from October 13, 1999 through January 21, 2020. Heteroskedasticity-consistent standard errors are reported in parentheses. ${ }^{*},{ }^{* *}$, and ${ }^{* * *}$ denote significance at $10 \%, 5 \%$, and $1 \%$, respectively. Constant terms are included in regressions but not shown in the table

surprises. $^{27}$ Unlike the case of the US, however, not much evidence on the information effects is available in the case of Japan. Therefore, to justify the conjecture on the presence of information effects in our regression, further investigation is required.

\section{Conclusion}

Using high-frequency data of futures rates, we measure the monetary policy surprises around the timings of the policy announcements by the Bank of Japan and estimate their effect on asset prices in Japan. Following the method of Gürkaynak et al. (2005) in identifying the two factors in monetary policy surprises,

\footnotetext{
27 Furthermore, Nakamura and Steinsson (2018) interpret the positive response of the 1-year-ahead output growth forecast in the private sector to a tightening monetary policy surprise as the evidence of the information effect.
} 
we find that a surprise monetary tightening has negative effects on the stock returns and positive effects on the yield curve, which is consistent with the theoretical predictions. Another finding is that the coefficients on both the target and path factors in the longer term JGB yield regressions tend to be larger than those in the shorter term JGB yield regressions. In particular, the effects of monetary policy surprises during the unconventional monetary policy period are the strongest for the 10-year JGB yield, which has been effectively targeted in the last 2 decades by the Bank of Japan. This finding differs from the previous studies using the data from the conventional monetary policy period, because the estimated coefficients are typically larger in the regression of the shorter term government bond yields. On the whole, our estimation results suggest that the target and path factors we construct are useful in evaluating the role of monetary policy shocks during the unconventional monetary policy period in Japan.

There are several directions in which this study could be extended. One could use the policy surprise measure obtained from the high-frequency data as an external instrument to estimate the aggregate responses to monetary policy shocks in a vector autoregression framework, as in the analysis conducted by Gertler and Karadi (2015), among others. Such an extension has been considered in a separate paper by Kubota and Shintani (2021). Another possible direction of an extension would be to identify an additional factor that represents the information effect, using the data for the intraday comovements of futures rates and the stock prices (Cieslak and Schrimpf 2019). These extensions remain for future work.

\section{Appendix A: Data sources}

- EYF3, EYF6, EYF9, EYF12 (3-month Euroyen futures): the CQG Data Factory (September 23, 1999-April 27, 2003) and the Tokyo Financial Exchange (April 28, 2003-).

- JGBF (10-year JGB futures): the Japan Exchange.

- TOPIX: the Japan Exchange.

- Nikkei 225: Nikkei NEEDS Tick Data (-2019) and CQG Data Factory (2020-).

- JGB1Y, JGB2Y, JGB5Y, JGB10Y, JGB20Y (the 1-, 2-, 5-, 10-, and 20-year JGB yields): REFINITIV.

For Euroyen futures, we use only the contract with a remaining maturity of more than 14 days. For example, EYF3 contains information from the Euroyen futures for which a contract can have as little as 14 days to expiration and as much as 3.5 months to expiration, with an average horizon of 2 months. Similarly, EYF6, EYF9, and EYF12 have on average 5, 8, and 11 months, respectively, to expiration. On expiration, Euroyen futures settle on the 3-month TIBOR, so that EYF3, EYF6, EYF9, and EYF12 represent on average the current expectation of the 3-month interest rate after 2, 5, 8, and 11 months, respectively. We also note that Euroyen futures have expiration dates that fall about 2 weeks before the end of each quarter. For this reason, we measure, for example, the EYF3 surprises for January and 
February by the March contract, from March to May by the June contract, from June to August by the September contract, from September to November by the December contract, and for December by the next-March contract.

The intraday data of Euroyen futures with the contract month of March 2000 are missing in our dataset. Therefore, the following surprises related to futures for March 2000 are replaced with the corresponding daily surprises. First, for EYF3 surprises from December 1999 through February 2000, there are 4 MPMs (December 17, 1999, January 17, 2000, February 10, 2000, and February 24, 2000) and 3 press conferences (December 21, 1999, January 19, 2000, and February 15, 2000). Second, for EYF6 surprises from September 1999 through November 1999, there are 4 MPMs (October 13, 1999, October 27, 1999, November 12, 1999, and November 26, 1999) and 5 press conferences (September 26, 1999, September 28, 1999, October 13, 1999, October 15, 1999, and November 16, 1999).

\section{Appendix B: Details on measuring monetary policy surprises}

This appendix describes the procedure in computing the policy surprises and highfrequency changes in asset prices around the monetary policy announcements from the intraday data in detail. Table 7 shows the trading hours for Euroyen futures, JGB futures, and stocks (TOPIX and Nikkei 225). Note that JGBs are not included in the table, because they are traded over the counter with no trading hours or breaks. When we construct the 30-min windows, the following three issues need to be taken into consideration: (1) trade breaks; (2) closing time; and (3) the event with an interval.

First, Table 7 shows that there are breaks in trading assets in the Japanese market. For example, there is a trade break between 11:30 a.m. and 12:30 p.m. in the Euroyen futures market. If the 30-min window around the time of the policy announcement overlaps with a trade break, changes in prices may not fully reflect the market surprises. In an extreme case, if the entire 30-min window is included in a trade break, no market surprise can be detected at all. To avoid this issue, we modify the windows, so that 30 min of trading hours will certainly be included to evaluate the change in prices. For instance, when the MPM statement is released at 12:20 p.m., we take the difference between the price at 12:50 p.m. and the price at 11:20 a.m in calculating the EYF surprises.

Second, a monetary policy event occurs in some cases after the financial markets close. For example, on November 30, 2011, the press release was issued at 10:00 p.m. when the Euroyen futures and the Tokyo stock market closed. On some dates when the MPM is held, the Euroyen futures market extends the closing time to wait for the MPM press release, and the exact closing time for each date is not publicly available. In such a case, we modify the surprise by taking the difference between the closing price on the day and the opening price on the next business day. Moreover, it is also possibly the case that while the event itself occurs before the market closed, the end of the window falls after the closing time. In such a case, we take the 
Table 7 Trading hours in Euroyen futures, JGB futures, and stock markets

\begin{tabular}{ll}
\hline Market & Trading hours \\
\hline Euroyen futures & 8:45 a.m.-11:30 a.m., 12:30 p.m.-8:00 p.m. \\
& $(8: 45$ a.m.-11:30 a.m., 12:30 p.m.-6:00 p.m. until February 4, 2007) \\
& 8:45 a.m.-11:02 a.m., 12:30 p.m.-3:02 p.m., 3:30 p.m.-5:30 a.m. \\
JGB futures & $(9: 00$ a.m.-11:00 a.m., 12:30 p.m.-3:00 p.m., 3:30 p.m.-6:00 p.m. \\
& until November 20, 2011) \\
Stocks (TOPIX, Nikkei 225) & 9:00 a.m.-11:30 a.m., 12:30 p.m.-3:00 p.m. \\
& $(9: 00$ a.m.-11:00 a.m., 12:30 p.m.-3:00 p.m. until November 20, 2011)
\end{tabular}

Note: For the JGB futures, the closing time of the night session has been extended several times. It was first extended on November 21, 2011 from 6:00 p.m. to 11:30 p.m., then extended to 3:00 a.m. on March 24, 2014, and finally extended to 5:30 a.m. on July 19, 2016 ("Celebrating 30 Years of JGB Futures," Osaka Exchange, Inc)
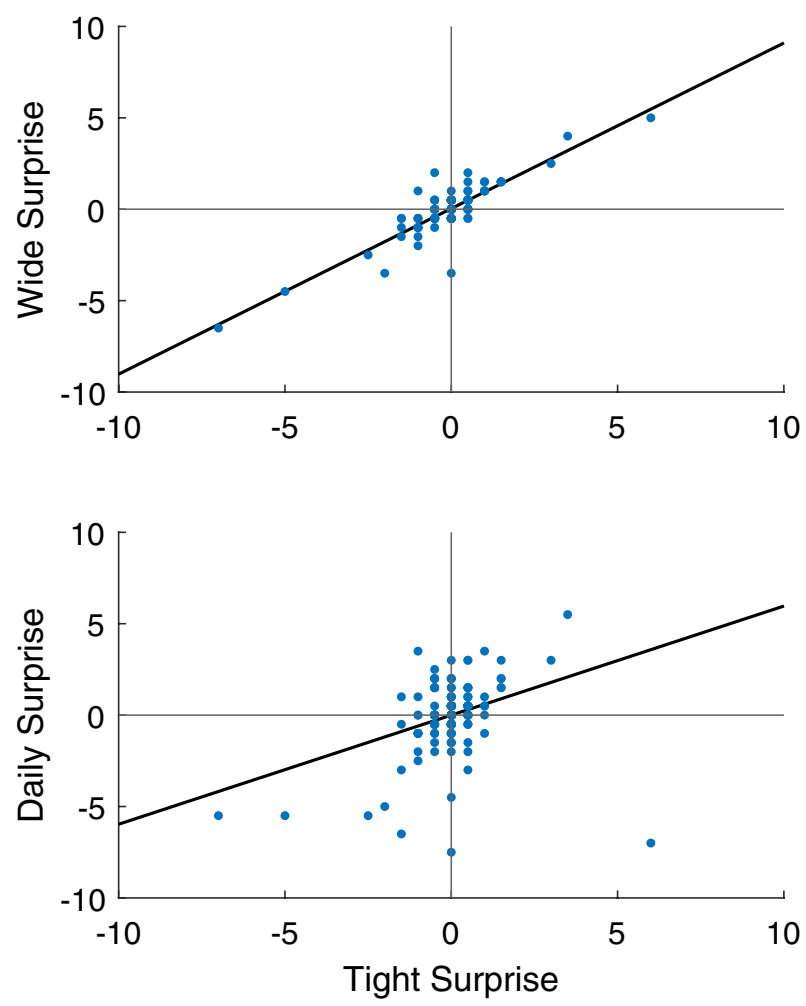

Fig. 8 Monetary policy surprises: comparison with alternative windows. Note: The left and right panels show the EYF3 surprises around 280 press releases from October 13, 1999 through January 21, 2020, respectively. The horizontal axes show the tight surprises, and the vertical axes show the wide and daily surprises. The unit of every axis is a basis point. The least-squares fitted lines are also shown 
Table 8 Monetary policy surprises: descriptive statistics

\begin{tabular}{|c|c|c|c|c|}
\hline \multicolumn{3}{|c|}{ UMP period (1999-2020) } & \multicolumn{2}{|c|}{ CMP period (1989-1999) } \\
\hline Tight & Wide & Daily & Daily & $\begin{array}{l}\text { Honda } \\
\text { and Kuroki } \\
(2006)\end{array}$ \\
\hline-0.013 & 0.025 & -0.009 & -1.463 & -1.451 \\
\hline$(0.050)$ & $(0.052)$ & $(0.084)$ & $(0.798)$ & $(2.340)$ \\
\hline 0.842 & 0.873 & 1.401 & 7.225 & 16.713 \\
\hline 280 & 280 & 280 & 82 & 51 \\
\hline
\end{tabular}

Note: "UMP Period" and "CMP Period" refer to the unconventional monetary policy and the unconventional monetary policy periods, respectively. All the surprises other than those used in the last column are measured with EYF3. The means and the standard errors are expressed by basis points. The second row in the parentheses shows the standard errors. For the details of each series, refer to texts and the footnotes in Fig. 2

difference in the price at the beginning of the window and the opening price on the next business day.

Third, some events associated with the MPM involve an interval rather than a point in time. For example, on January 21, 2020, the governor's post-MPM press conference began at 3:30 p.m. and ended at 4:20 p.m., so that the total time of the press conference was $50 \mathrm{~min}$. In such cases, we set the surprise window as an interval from $10 \mathrm{~min}$ before the event begins until $20 \mathrm{~min}$ after the event concludes. In the example above, the window extends from 3:20 p.m. to 4:40 p.m.

\section{Appendix C: Window size comparisons}

In this appendix, we compare the monetary policy surprise measures from different windows and report the statistical properties of the policy surprise measures in the conventional and unconventional monetary policy periods.

Figure 8 compares the surprise measures using three alternative windows, in which the left panel and the right panel show the comparison for EYF3 surprises, respectively. The top panel compares the tight surprises and the wide surprises, and the bottom panel compares the tight surprises and the daily surprises. The figure shows that all three surprises are positively correlated. The tight surprises and the wide surprises move closely to each other, but there seems to be deviations between the daily surprises and the tight surprises. This observation suggests that the daily surprises are likely to be influenced by news unrelated to the monetary policy announcements.

The first three columns of Table 8 show the descriptive statistics of EYF3 surprises, expressed in the unit of basis points, using alternative windows around press releases. We observe that the surprises are unbiased around mean zero and the standard deviation is the smallest for the tight surprises. While not shown in the 
table, the $F$-statistic of 2.768 suggests that the null hypothesis of the same standard deviations for the daily surprises and tight surprises is rejected in favor of a larger standard deviation for the daily windows surprises at the $1 \%$ significance level. At the same time, the null hypothesis of the same standard deviations between the wide surprises and the tight surprises is not rejected at the $10 \%$ level with the $F$-statistic of 1.076. This outcome implies that daily surprises are likely to contain surprises from news not related to the monetary policy.

Funding This research was funded by Grant-in-Aid for Scientific Research No. $20 \mathrm{H} 01482$.

\section{References}

Altavilla, C., Brugnolini, L., Gürkaynak, R. S., Motto, R., \& Ragusa, G. (2019). Measuring euro area monetary policy. Journal of Monetary Economics, 108, 162-179.

Arai, N. (2017). The effects of monetary policy announcements at the zero lower bound. International Journal of Central Banking, 13(2), 159-196.

Cieslak, A., \& Schrimpf, A. (2019). Non-monetary news in central bank communication. Journal of International Economics, 118, 293-315.

Cragg, J. G., \& Donald, S. G. (1997). Inferring the rank of a matrix. Journal of Econometrics, 76(1-2), $223-250$.

Gertler, M., \& Karadi, P. (2015). Monetary policy surprises, credit costs, and economic activity. American Economic Journal: Macroeconomics, 7(1), 44-76.

Gürkaynak, R. S., Sack, B., \& Swanson, E. T. (2005). Do actions speak louder than words? The response of asset prices to monetary policy actions and statements. International Journal of Central Banking, $1(1), 55-93$.

Hattori, T. (2019). Estimation of CCP premium during the financial crisis of 2008: Evidence from Japanese government bond market. Available at SSRN. https://doi.org/10.2139/ssrn.3118042.

Honda, Y., \& Kuroki, Y. (2006). Financial and capital markets responses to changes in the central bank's target interest rate: The case of Japan. The Economic Journal, 116(513), 812-842.

Jarociński, M., \& Karadi, P. (2020). Deconstructing monetary policy surprises-the role of information shocks. American Economic Journal: Macroeconomics, 12(2), 1-43.

Koeda, J. (2017). Bond supply and excess bond returns in zero-lower bound and normal environments: Evidence from Japan. The Japanese Economic Review, 68(4), 443-457.

Kubota, H., \& Shintani, M. (2021). Macroeconomic effects of monetary policy in Japan: An analysis using interest rate futures surprises. The University of Tokyo Working Paper.

Kuttner, K. N. (2001). Monetary policy surprises and interest rates: Evidence from the fed funds futures market. Journal of Monetary Economics, 47(3), 523-544.

Nakamura, E., \& Steinsson, J. (2018). High-frequency identification of monetary non-neutrality: The information effect. The Quarterly Journal of Economics, 133(3), 1283-1330.

Nakamura, F., Sudo, N., \& Sugisaki, Y. (2021). A quest for monetary policy shocks in Japan by high frequency identification. Bank of Japan IMES Discussion Paper, No. 2021-E-2.

Nakashima, K., Shibamoto, M., \& Takahashi, K. (2020). Identifying quantitative and qualitative monetary policy shocks. Available at SSRN. https://doi.org/10.2139/ssrn.2960272.

Rogers, J. H., Scotti, C., \& Wright, J. H. (2014). Evaluating asset-market effects of unconventional monetary policy: A multi-country review. Economic Policy, 29(80), 749-799.

Swanson, E. T. (2021). Measuring the effects of Federal reserve forward guidance and asset purchases on financial markets. Journal of Monetary Economics, 118, 32-53.

Publisher's Note Springer Nature remains neutral with regard to jurisdictional claims in published maps and institutional affiliations. 